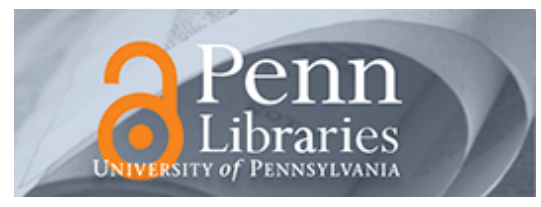

University of Pennsylvania

ScholarlyCommons

Management Papers

Wharton Faculty Research

$9-2010$

\title{
Prior Alliances With Targets and Acquisition Performance in Knowledge-Intensive Industries
}

\author{
Akbar Zaheer \\ Exequiel Hernandez \\ University of Pennsylvania \\ Sanjay Banerjee
}

Follow this and additional works at: https://repository.upenn.edu/mgmt_papers

Part of the Business Administration, Management, and Operations Commons

\section{Recommended Citation}

Zaheer, A., Hernandez, E., \& Banerjee, S. (2010). Prior Alliances With Targets and Acquisition Performance in Knowledge-Intensive Industries. Organization Science, 21 (5), 1072-1091. http://dx.doi.org/10.1287/ orsc. 1100.0528

At the time of publication, author Exequiel Hernandez was affiliated with Carlson School of Management, Minneapolis. Currently, he is a faculty member at the Management Department at the University of Pennsylvania.

This paper is posted at ScholarlyCommons. https://repository.upenn.edu/mgmt_papers/118

For more information, please contact repository@pobox.upenn.edu. 


\title{
Prior Alliances With Targets and Acquisition Performance in Knowledge-Intensive Industries
}

\begin{abstract}
An important focus of the research on mergers and acquisitions is the conditions under which acquisitions create value for the acquiring firm's shareholders. Given that the acquisition process is plagued by serious issues of information asymmetry, which are exacerbated in the context of knowledge acquisitions, we examine whether prior alliances with potential targets reduce the information asymmetry enough to create "partner-specific absorptive capacity" and yield superior stock returns on acquisition, compared with acquisitions not preceded by alliances. We test our hypotheses on a sample of hightechnology acquisitions by U.S. firms during 1990-1998 using an event study methodology to assess abnormal stock returns. We find, unexpectedly, that no significant general effect emerges for acquisitions with prior alliances. However, international acquisitions following alliances show significantly better returns relative to both acquisitions without prior alliances and domestic acquisitions. Additionally, stronger forms of prior alliances lead to better acquisition performance than weaker forms of alliances. Together, the results broadly support our thesis that partner-specific absorptive capacity may be at work and suggest that under certain prior alliance conditions, acquisitions can indeed create value for acquirers.
\end{abstract}

\section{Keywords}

alliances, mergers and acquisitions, acquisition performance, partner-specific absorptive capacity, information asymmetry, strong alliances, knowledge-intensive industries

\section{Disciplines}

Business Administration, Management, and Operations

\section{Comments}

At the time of publication, author Exequiel Hernandez was affiliated with Carlson School of Management, Minneapolis. Currently, he is a faculty member at the Management Department at the University of Pennsylvania. 


\section{Prior Alliances with Targets and Acquisition Performance in Knowledge-Intensive Industries}

Article in Organization Science · October 2010

Impact Factor: $4.34 \cdot$ DOI: 10.1287 /orsc.1100.0528 $\cdot$ Source: DBLP

CITATIONS

37
READS

27

3 authors, including:

Sanjay Banerjee

University of Alberta

3 PUBLICATIONS 37 CITATIONS

SEE PROFILE 


\title{
PRIOR ALLIANCES WITH TARGETS AND ACQUISITION PERFORMANCE IN KNOWLEDGE-INTENSIVE INDUSTRIES
}

\author{
Akbar Zaheer \\ University of Minnesota \\ Carlson School of Management \\ 3-365 - 321 19th Avenue South \\ Minneapolis, MN 55455 \\ (612) 626-8389 \\ e-mail: azaheer@umn.edu
}

\author{
Exequiel Hernandez \\ University of Minnesota \\ Carlson School of Management \\ 3-365 - 321 19th Avenue South \\ Minneapolis, MN 55455 \\ (612) 625-7805 \\ e-mail: herna136@umn.edu
}

\author{
Sanjay Banerjee \\ University of Minnesota \\ Carlson School of Management \\ 3-365 - 321 19th Avenue South \\ Minneapolis, MN 55455 \\ (612) 626-1812 \\ e-mail: bane0032@umn.edu
}

Acknowledgments: We thank Myles Shaver, David Souder, and Sri Zaheer for helpful comments at earlier stages of this project. We are grateful for the comments and guidance of Senior Editor Steve Borgatti and the three anonymous reviewers. We acknowledge the valuable research assistance of Young-Jae Choi, Hussain Dalal, Jungkeun Kim and Li-Kuo Sung. A version of this paper was presented at the Academy of Management Meetings, in Hawaii, August, 2005. 


\title{
Prior Alliances with Targets and Acquisition Performance in Knowledge-Intensive Industries
}

\begin{abstract}
An important focus of the research on mergers and acquisitions is the conditions under which acquisitions create value for the acquiring firm's shareholders. Given that the acquisition process is plagued by serious issues of information asymmetry, which are exacerbated in the context of knowledge acquisitions, we examine whether prior alliances with potential targets reduce the information asymmetry enough to create 'partner-specific absorptive capacity' and yield superior stock returns upon acquisition compared to acquisitions not preceded by alliances. We test our hypotheses on a sample of high-technology acquisitions by US firms during 1990-98 using an event study methodology to assess abnormal stock returns. We find, unexpectedly, that no significant general effect emerges for acquisitions with prior alliances. However, international acquisitions following alliances show significantly better returns relative to both acquisitions without prior alliances and to domestic acquisitions. Additionally, stronger forms of prior alliances lead to better acquisition performance than weaker forms of alliances. Together, the results broadly support our thesis that partner-specific absorptive capacity may be at work and suggest that under certain prior alliance conditions, acquisitions can indeed create value for acquirers.
\end{abstract}

Key words: Alliances; Mergers and Acquisitions; Acquisition performance; Partner-specific absorptive capacity; Information asymmetry; Strong alliances; Knowledge-intensive industries. 
Whether and how acquisitions create economic value are key questions in strategy research (Haspeslagh and Jemison 1991; Hitt et al. 2001). Empirical evidence shows that acquisitions are generally unremunerative for the shareholders of the acquiring firm (Sirower 1997), averaging zero or even slightly negative returns, despite the existence of supposed synergies (Andrade et al. 2001; Bradley et al.1988; Jensen and Ruback 1983). However, while most studies agree that acquirers on average break even at best, few dwell on the fact that behind the mean of zero there exists a sizable variance. There are plentiful instances where shareholders of the successful acquirers earn large positive returns (e.g. Cisco, GE, Intel), while other acquisitions (e.g. IBM-Lotus or Novel-Word Perfect) generate significant losses for acquiring firm shareholders (Capron and Pistre 2002). Thus, an area of considerable interest in strategy research is concerned with the conditions under which acquirers earn superior returns.

Earning superior returns from the acquirer's perspective becomes even more of a challenge if the target firm is a knowledge-intensive one. We define a knowledge-intensive firm as one that has significant knowledge-based assets, which consist of proprietary knowledge (e.g. patents, trade marks, trade secrets and so on) and tacit knowledge residing in individual employees' minds or embedded in organizational routines, experience, processes or networks. Although one of the key motivations behind corporate acquisition is gaining access to the knowledge-based assets of the target firm (Barney 1988, Chi 1994, Haspeslagh and Jemison 1991), acquiring knowledge assets poses serious organizational and management challenges because knowledge may be tacit (Polanyi, 1963) and embedded in individual, group, organization, or network levels; or intertwined and 'bundled' with other resources (Nonaka1994, Nonaka and von Krogh 2009). Such embedding and bundling, along with tacitness, makes knowledge difficult to acquire or appropriate in factor markets or otherwise (Coff 1999, Kogut and Zander 1992, Liebeskind 1996, Mowery et al. 1996). More broadly, theory suggests that problems associated with acquiring knowledge-based assets are primarily twofold: ex ante market failure due to information asymmetry (Arrow 1974; Balakrishnan and Koza 1993; Teece 1980; Williamson 1985) between the acquiring and the target firms; and ex post organization failure due to the difficulty in integrating the target firm's knowledge assets into the acquiring firm after the acquisition (Hennart 1988, Hennart and 
Reddy 2000, Puranam et al. 2009) . Together, the set of ex ante and ex post problems make knowledge acquisitions particularly challenging.

Thus, an important issue facing potential knowledge acquirers, and researchers studying the question, is ascertaining what might be potential solutions to the problems of properly assessing the value of, and subsequently integrating, knowledge-based assets, and how effective the solutions are. One option to deal with such apparent market failure (Teece 1980) may be to limit the acquisition of knowledgeintensive target firms. However, anecdotal evidence and academic literature suggest that, to the contrary, firms' recent acquisitions seem to focus to an even greater extent than previously on knowledge-intensive acquisitions in industries such as business and health services, software, and precision medical equipment (Mergers \& Acquisitions 1999).

Prior studies suggest that acquirers of knowledge-based assets take steps to reduce the information asymmetry problem by forming prior alliances with the target, which can be used as intermediate pre-acquisition strategic options. That is, an alliance can be used to reduce information asymmetry by learning more about the target's assets and assessing their true value before deciding on an acquisition. For example, Bowman and Hurry (1993) use an option lens to explain the strategy of sequentially exercising small investments in alliances and waiting for an opportune time to strike the option of acquisition. In the high-technology Application Specific Integrated Circuits industry, Vanhaverbeke et al. (2002) find that a series of strategic alliances between partners increased the probability that one partner would ultimately acquire the other. However, this study does not investigate whether or not the prior alliances affected acquisition performance.

Research evidence to date on the effect of prior alliances on acquisition performance has been mixed. Porrini (2004) examines the effect of having alliances with targets prior to acquisitions on the ROA (return on assets) of the acquiring firm. While Porrini finds that post-acquisition ROA is improved when acquirers have previous alliances with target firms, the dataset in her study is restricted by being limited to only acquisitions of public targets in the manufacturing sector, which comprise a mere $15 \%$ of technology acquisitions. However, recent research (Uhlenbruck et al. 2006) showing that no general 
effect exists for alliances prior to acquisitions offers a contrasting view and a precedent for the notion that the effect of prior alliances may be contingent on other factors, although these scholars do not investigate what the other factors may be. Thus, there are good reasons to investigate the issue more thoroughly.

In the current paper, we advance extant research by elucidating the conditions under which forming prior alliances with targets lead to improved acquisition performance. Besides assessing the main effects of this strategy on performance, we examine whether prior alliances are particularly useful in international contexts (where information asymmetry is pronounced) or when the alliance involves intense interaction between the partners before the acquisition. Our sample includes all targets—public and private - in both manufacturing and service high-technology (high-tech) sectors, and in a further distinction from Porrini (2004) we use the event study methodology to assess acquisition performance. Though not without limitations, this methodology has the advantage of isolating the performance effects of the acquisition event more directly than does ROA, and has been extensively used in acquisition studies in the strategy literature (e.g., Seth 1990; Singh and Montgomery 1987).

Our findings are interesting in that the main effect differs from that of Porrini (2004) - we find no general impact of prior alliances on acquisition performance. However, we find nuanced results which suggest that prior alliances with acquisition targets can, under conditions of exacerbated information asymmetry or of intense interaction amongst partners, produce superior acquisition performance. In particular, we find that international acquisitions with prior alliances create greater shareholder value, as do acquisitions that follow stronger forms of alliances, than comparable acquisitions without prior alliances. In the rest of this paper, as is customary, we begin with theory and hypotheses below, before proceeding to the methods, results, and discussion.

\section{THEORY AND HYPOTHESES}

As mentioned earlier, theory suggests that two sets of problems are associated with acquiring knowledgebased assets: ex ante problems from market failure due to information asymmetry between the acquiring 
and the target firms; and ex post organization failure due to the problems of integrating the target firm's knowledge assets into the acquiring firm after the acquisition has taken place. We discuss each below.

\section{Problems of Information Asymmetry}

Ex-ante market failure arises because acquirers usually possess less accurate information about the quality and value of the knowledge-based assets of a potential target than the target itself does. More specifically, information asymmetry between the acquiring and the target firm creates uncertainty about the quality and value of the target firm's assets, leading to problems of adverse selection (Akerlof 1970). In other words, available potential targets could well be 'lemons' (intrinsically of poor quality), while those of better quality may be available only at prices higher than buyers are prepared to pay. The notion of information asymmetry in this context hinges on the fundamental imbalance in the information possessed by the potential acquirer and target firms, as opposed to the simple insufficiency of knowledge about the potential target held by the potential acquirer.

Potential acquirers have much less information about the quality of a firm's knowledge base than about its tangible assets and physical capital because knowledge-based assets are harder to assess and appraise than are tangible assets (Chi 1994) and financial statements provide scant information about intangible knowledge assets. Typically, accurate information about the quality, performance characteristics, and value of the knowledge assets of the target firm is not common knowledge. Preacquisition due diligence does not resolve the problem either, as the potential for information asymmetry allows self-interested sellers and their agents to opportunistically misrepresent the true value of their firms, causing the acquiring firm to incur extra costs in identifying lemons and safeguarding themselves against misrepresentation. This makes potential acquirers - the buyers of such assets - uncertain about the 'true' value of the target.

Even if misrepresentation is unintentional, the difference in the knowledge held by the acquirer and target firms creates an information asymmetry issue. For example, a software developer target might be overly optimistic regarding the timeline for the release of a major new generation of its software. In 
such cases, it would be difficult for the potential acquirer to obtain an accurate idea of the stage and state of the future release beyond the alleged release date. If an acquirer's decision to purchase the software developer hinged on the successful release of the new product, the misrepresentation, whether intentional or not, would greatly affect subsequent acquisition performance. The success of such a knowledge acquisition would hinge significantly not only on the actual time to project completion, but also on subtle but key characteristics of the target firm such as its capabilities, skills, culture and how these dimensions complement those of the potential acquirer-which are difficult to assess ex ante.

Coff (1999) identifies three types of uncertainty regarding the target firm's knowledge-based assets: (i) uncertainty about the quality of assets, since these may include significant tacit elements; (ii) uncertainty about what can be transferred, since even if the acquiring firm is able to ascertain asset quality substantial uncertainty exists about what part and how much of these assets can actually be transferred to the acquirer post acquisition; and (iii) uncertainty about the prospects for synergy. Prospective synergy is about seeing the future potential without being able to directly observe and assess the combined capabilities of the acquiring and the target firms and thus, by definition, is speculative. In their classic work on acquisitions, Haspeslagh and Jemison (1991) note that it is difficult to specify, ex ante, how much knowledge can be transferred and whether the knowledge can be utilized in a new setting, even if the target cooperates enthusiastically. The information asymmetry about the target's knowledge assets and uncertainty about its value make buyers often overvalue knowledge assets in their excitement and enthusiasm for 'winning' the acquisition over competing bidders. The eventual acquirer frequently ends up 'accursed' ('the winner's curse') by paying more than the target assets are worth (Giliberto and Varaiya 1989). In fact, research has shown that greater premiums may hurt post-acquisition performance (Krishnan et al. 2007).

\section{Problems in Post-Acquisition Integration}

Knowledge, in particular the tacit variety, resides inside individuals' minds, is embedded in organizational routines, experience, and networks (Nonaka 1994, Nonaka and von Krogh 2009) as well as 
bundled with other resources. Consequently, acquiring firms find it difficult to extricate knowledge assets out from the target and disentangle the desirable assets from the undesirable ones. As suggested by the socalled 'indigestibility' argument, ex post transaction costs are high when desired assets are 'comingled' in this way, leading to poor post-acquisition integration (Hennart 1988; Hennart and Reddy 1997).

Moreover, the acquisition contract is often incomplete and lacks the binding power to ensure a complete transfer of the intangible assets of the target firm (Williamson 1985). The acquiring firm usually has little recourse in dealing with the target firm's ex post opportunism in withholding tacit information. A further post-acquisition problem that acquiring firms face involves the retention of target firm scientists and executives, since talent often represents one of the critical strategic assets acquirers hope to obtain from the target, particularly in the case of knowledge-intensive acquisitions (Jemison and Sitkin 1986). When managers and scientists leave the target following an acquisition, critical knowledge assets, as well as knowledge about the target company and its operating environment, are lost (Walsh 1988).

Integration of target assets into the acquiring firm also entails several other problems, including lack of knowledge of the target assets and difficulty in finding and transferring such assets into the acquiring firm (Puranam et al. 2006, 2009). Often what is promised or understood during pre-acquisition negotiation or the due diligence process does not match with what is 'discovered' in the target company post acquisition. Furthermore, even if the acquiring firm identifies the promised assets in the target firm, the tacitness of knowledge assets makes them extremely difficult (or 'sticky') to transfer even within the same organization (Szulanski 1996, Nonaka and von Krogh 2009), let alone across organizational boundaries to another firm (Nonaka and Takeuchi 1995).

In sum, the acquisition of knowledge assets is complicated by significant information asymmetry problems, both ex ante and ex post. We present arguments below to suggest that prior alliances with target firms may alleviate these problems. 


\section{Prior Alliances and Partner-specific Absorptive Capacity}

Alliances are voluntarily-initiated cooperative agreements between firms that involve mutual investment, exchange, sharing, or co-development of products, technologies, or services (Gulati 1998). A strategic alliance in the form of a joint venture, for instance, helps a firm learn valuable information about its partner's resources, capabilities, and reliability. In this vein, Balakrishnan and Koza argue that joint ventures "can induce information revelation and mitigate the adverse selection problem. There may be short-term gains from misrepresentations, but the threat of termination of the joint-venture or its potential liquidation because of the resulting downstream inefficiencies, will offset these gains and reduce the incentives to misrepresent" (1993: 103-104). A prior alliance with the target can provide the acquiring firm with detailed information about the organization which allows the acquirer to assess how much synergy to expect, how much the target is worth, and in the end, whether or not to acquire the target (Burt 1992; Gulati 1999). Moreover, a prior alliance with the target also helps the acquirer understand the target's potential compatibility with the acquirer, both strategically and organizationally (Kale et al.

2000). Research shows that a lack of compatibility or misfit in culture, strategy, or business practices can seriously compromise acquisition performance (Chatterjee et al. 1992). Prior alliances with targets allow acquiring firms to avoid such costly mistakes.

Strategic alliances offer partners the opportunity to learn from and about each other, which has been shown to be an important element of alliance value creation (Anand and Khanna 2000a; Inkpen 1998, Sarkar et al. 2009). Alliances facilitate learning when partners absorb and exchange information, capabilities, and skills from and with each other (Kale et al. 2000; Khanna et al. 1998). A prior alliance with the target can provide the acquiring firm with 'absorptive' and 'communicative' capabilities (Larsson et al. 1998), which may help the acquirer develop strategies, routines, and capabilities to better access and exchange resources with the target post acquisition (Dyer and Singh 1998, Kale et al. 2000). A prior target alliance thus helps the acquiring firm develop knowledge related to the specific alliance partner firm, which scholars have referred to as 'partner-specific absorptive capacity' (Dyer and Singh, 1998, Gulati et al. 2008). Other scholars have discussed similar notions using terms such as 'partner- 
specific alliance experience' (Hoang and Rothaermel, 2005) and 'interorganizational routines' (Zollo et al., 2002).

The concept of partner-specific absorptive capacity implies that "a firm has developed the ability to recognize and assimilate valuable knowledge from a particular alliance partner" (Dyer and Singh, 1998: 665; italics in the original). The concept draws on the overall idea of absorptive capacity, which in this setting refers to the acquiring firm's capacity to identify, internalize, assimilate and apply knowledge from an external source (Cohen and Levinthal 1990); in our case, the potential target. Partner-specific absorptive capacity, developed through a prior alliance with the target, can also help the acquirer to manage conflict in the post-acquisition phase better (Arino and Torres de la 1998). Thus, such targetspecific knowledge capital helps an acquirer identify the relevant knowledge resources that exist in the target, 'disentangle' the desirable knowledge assets from the undesirable ones (i.e. overcome 'indigestibility'), develop knowledge-sharing routines to improve learning efficiency, and better manage conflict during the post-acquisition process, thereby leading to more successful post acquisition integration outcomes.

A prior alliance with the target can also build mutual trust between the partners which eventually helps the acquiring firm better integrate the target following the acquisition. Previous studies suggest that prior repeated ties enhance trust between partners (Gulati 1995). Zaheer et al. (1998) find that trust reduces negotiating costs and also improves alliance performance. Kale et al. (2000) argue that 'relational capital,' developed through mutual trust and interaction at the individual level between alliance partners, forms the basis for learning and know-how transfer across partners. Trust between the acquiring and the acquired firm not only enhances the efficacy of knowledge absorption and exchange between the partners post acquisition, but also creates a sense of belonging among the acquired scientists and executives that may induce them to remain in the acquired firm after the acquisition (Finkelstein et al. 1998), and facilitates value creation through active participation by acquired managers in the post-acquisition integration process (Graebner 2004). In knowledge-intensive industries, the managers and scientists are the primary knowledge assets, and often the main objective of the acquisition is to gain access to the 
target's key employees. Thus, a prior alliance with the target helps acquiring firms retain target employees by building target-specific relational capital which eventually enhances post-acquisition integration performance.

In fact, extant literature in strategy suggests that strategic alliances sometimes end in acquisitions (Kogut 1988, Bleeke and Ernst 1993, Garette and Dussauge 2000). Consistent with these empirical findings, Haspeslagh and Jemison (1991) note: "In many cases, collaboration is the first productive step toward understanding the business, market, or industry before a complete acquisition" (p. 247). Studies have also suggested that firms can use prior alliances as intermediate strategic options (Kogut 1991, Bowman and Hurry 1993) to eventually acquire the partner. However, none of the above-mentioned studies examine whether acquisitions after prior alliances actually influence acquisition performance.

In sum, we argue that prior alliances with targets can improve acquisition performance by creating partner-specific absorptive capacity and thereby ameliorating the two main problems associated with acquiring knowledge-intensive targets: ex ante market failure due to information asymmetry between the acquiring and the target firm and the ex post integration problems of integrating knowledge assets. Thus we hypothesize,

H1: Acquisitions with prior target alliances will perform better than acquisitions without prior target alliances.

\section{Prior Alliances with International Targets}

A long tradition of literature in international management attests to the costs and difficulties of doing business abroad (Hymer 1960). These arise not only from geographic distance, but also from cultural, institutional, and social differences between the home and the host countries. Discrimination against foreign firms and issues of legitimacy crop up as well to create a sizeable barrier to success in international operations, which together have been termed the 'liability of foreignness' (Zaheer 1995).

We argue that the liability of foreignness is further compounded in the context of knowledge acquisitions. Not only are international knowledge acquisitions plagued by all the problems of knowledge acquisitions in general, but information asymmetry is further exacerbated because the context 
is foreign. A lack of understanding of the local culture, politics, society, and institutions, as well as foreign market and competitive conditions, business practices, and success factors, contributes to greater 'psychological distance' (Johanson and Vahlne 1977). In turn, greater psychological distance adds to the difficulties of assessing the degree to which the international target possesses valuable knowledge assets, accurately evaluating what these may be worth, and the extent of any potential synergies with the acquirer's assets. Post-acquisition integration problems are also likely to be enhanced because disentangling the valuable from the irrelevant knowledge assets, and combining the desirable assets with those of the acquirer to create synergistic asset combinations is likely to be more difficult when knowledge resource holders are from a host country different from that of the acquirer (Capron et al. 1998, Hennart 1988).

In consequence, international alliances are likely to be particularly valuable in reducing the problems of knowledge asset information asymmetry because the benefits of increased partner-specific absorptive capacity are greater than in domestic settings (Robson et al. 2008). Alliances with local partners are not only likely to socialize international managers in the customs and business practices of the host country, thereby reducing psychological distance, but will also eventually contribute to a reduction in the liability of foreignness by enhancing the legitimacy of the acquiring home country firm which is now seen to be allied with a local one (Kostova and Zaheer 1999). Together, these processes will improve the acquirer's ability to ascertain the true value of the knowledge assets of the international target, as well as make it easier to disentangle and integrate the target's knowledge assets following the acquisition.

Some recent research provides support for this notion. Chen and Hennart (2004) find that since making acquisitions abroad involves high costs of target inspection and contract enforcement due to information asymmetry, foreign investors are more likely to form an equity alliance (i.e. a partial acquisition or an 'acquisition joint venture') with the target before they finally acquire it. However, this study did not examine whether those international acquirers with prior target alliances were more successful than others that did not form prior alliances. Research on international acquisitions also 
supports the thesis that, under certain conditions, international acquisitions create positive stockholder returns (Doukas and Travlos 1988; Markides and Ittner 1994), although these studies did not examine the effect of prior alliances as one of the antecedent conditions. We build on prior research by suggesting that one of the conditions that make international acquisitions more successful is the existence of a prior alliance with the international target. In sum, given the severe problems of information asymmetry in international knowledge contexts, and the likelihood that alliances with international firms are likely to contribute significantly to reducing them, we propose that international acquisitions will yield better returns when preceded by previous alliances with the target than when not preceded by such a relationship. Formally,

H2: When the target is an international firm, acquisitions with prior target alliances will perform better than acquisitions without prior target alliances.

The previous hypothesis compares international acquisitions that have not been preceded by alliances with international acquisitions that have been preceded by such alliances. We now make a further subtle distinction between international acquisitions that have been preceded by alliances and domestic acquisitions that have also been preceded by alliances. Here we argue that since information asymmetry between the potential target and acquirer firms is greater in international contexts than in domestic ones, while prior alliances help develop partner-specific absorptive capacity and learning for all acquisitions, the effect is likely to be stronger still when the acquisition is international relative to a domestic one. As well, the resource-based view of the firm (Barney, 1991) provides additional support for our logic. In essence, partner-specific absorptive capacity is likely to be harder to access in international settings than domestic ones. In domestic settings, partner firms will have similar knowledge and understandings of laws, institutions and operational issues which will enhance their ability to learn about each other. Consequently, while such partner-specific absorptive capacity will be easier and more likely to be created in domestic settings, it will also be less rare and therefore less valuable in terms of generating differential performance after an acquisition. In contrast, firms that are able to access partnerspecific absorptive capacity in international settings through their prior alliances will outperform 
acquirers in domestic settings, even though the latter have had prior alliances, because the partner-specific absorptive capacity they access will be rarer and therefore more valuable. Formally,

H3: Acquisitions with prior target alliances will perform better when the target is international than when it is domestic.

Taken together, these two hypotheses highlight that international acquisition strategies may not be superior to domestic ones per se - except when they are preceded by international alliances that convey knowledge and information, thereby reducing information asymmetries and creating partnerspecific absorptive capacity.

\section{Strength of Prior Alliances}

Although prior alliances have the potential to improve the acquiring firm's performance, not all types of alliances are likely to be equally effective at doing so. Our basic argument in this regard is that the ability to develop partner-specific absorptive capacity—which subsequently reduces information asymmetry between the potential target and acquirer-will be contingent upon the frequency and quality of prior interactions between the two firms, which in turn will be affected by the strength of the alliance relationship between them.

Research in alliances emphasizes the social process of exchange that characterizes strong tieswhich involve trust, commitment, cooperation, mutuality, and equity — and the positive alliance outcomes that arise from such elements of the alliance relationship (Granovetter 1985). Granovetter, in a classic work, defines the strength of a tie as based on a "combination of the amount of time, the emotional intensity, the intimacy (mutual confiding), and the reciprocal services which characterize the tie" (1973: 1361). When researching interfirm networks, scholars have typically drawn on Granovetter (1973) and focused on the amount of time and reciprocal services to measure the tie strength between firms (e.g. Nohria \& Garcia-Pont 1991; Rowley et al. 2000).

In empirical work, Nohria and Garcia-Pont (1991) suggest that the strength of alliance relationships can vary in terms of their relationship 'intensity,' which is determined by 'resource 
commitments, organizational interdependence, and the ease with which they [the alliances] can be dissolved" (p. 117). A stronger relationship thus involves higher degrees of resource commitments and of interdependence among partners which implies, among other things, greater levels of interaction in terms of both quantity and quality. Consider, for example, an R\&D joint venture compared to a licensing-only agreement. Due to the complex, unstructured, and uncertain nature of the joint task, the R\&D alliance is more likely to require organization members to work closely together with those from the partner organization and is thus likely to involve greater and richer interactions between alliance partners. In situations in which knowledge assets are required to be assessed, such an alliance is more likely to reduce information asymmetry between the partners than the weaker licensing-only alliance, in which the contractual agreement is typically more structured and less ambiguous, but also likely to present fewer opportunities for rich and deep interaction (Anand and Khanna, 2000b).

Strong interfirm ties possess two main advantages: they provide firms with fine-grained information and confer benefits of control. Extant research indicates that strong ties are associated with the exchange of fine-grained information across organizational boundaries (Uzzi 1999). The development of strong ties builds a foundation for the processing of this rich information. Further, even during the process of strengthening and deepening interfirm relationships to the level of strong ties, partners learn about each other's organizations and develop shared norms of behavior and a mutual understanding of each other (Larson 1992). Such intense social relations make the alliance partner's knowledge and information more available, credible, and interpretable. Close and intense interaction between the members of partner firms also serves as an effective mechanism for the transfer of sticky knowledge assets (Marsden 1990; von Hippel 1988). Learning efficiency and success in an alliance depend on an iterative process of exchange between the firms and the extent to which individual members of the partner firms engage in such interaction (Arrow 1974; Badaracco 1991). Thus, based on a deeper degree of partner-specific absorptive capacity stemming from intense interaction, information and knowledge that is tacit and holistic in nature can be more readily and efficiently accessed as well as transferred across organizational boundaries. 
Strong ties can also serve as part of a social control mechanism, which governs partner behavior in interfirm relationships. Strategic alliances are associated with a variety of risks and uncertainties (e.g. Hamel et al. 1989). Organizations entering alliances face considerable moral hazard concerns because of the unpredictability of the behavior of partners and the likely costs of opportunistic behavior, should it occur (Gulati 1999). Network scholars have shown that strong ties can incrementally promote and enhance trust, reciprocity, and a long-term perspective in a relationship (e.g. Larson 1992). By reducing the likelihood of opportunistic behavior, these elements can help to effectively mitigate the uncertainties arising from the moral hazard problem in strategic alliances. In this vein, as noted previously, Kale et al. (2000) argue that frequent and intense exchanges between the members of partner firms enhance trust, which in turn increases learning via norms of mutual gain and reciprocity between alliance partners (Powell 1990, Robson et al. 2008).

Consequently, we argue that stronger prior alliances will be more effective in improving subsequent acquisition performance than weaker prior alliances by reducing the information asymmetry between the acquiring and target firms because they foster learning and trust. These in turn help reduce ex ante information asymmetry to create more successful post-acquisition integration. Accordingly,

H4: Acquisitions with stronger prior alliances with targets will perform better than acquisitions with weaker prior alliances.

\section{METHODS}

\section{Data and Sampling Approach}

Our sample consists of high-tech acquisitions by US public firms in the period 1990-1998. We selected this time frame after a preliminary analysis of overall M\&A and alliance activity between 1990 and 2004. Figure 1 plots the number of high-tech acquisitions and alliances over this period, and shows there are two sharply different periods of activity. Initially, there is a steady increase in the number of acquisitions and alliances until 1998. This steady period is followed by one of high volatility, with a sharp three-year spike in acquisitions and alliances between 1999 and 2001, followed by an equally sharp drop thereafter. This latter time window between 1999 and 2004 corresponds to the "tech bubble" and the subsequent 
instability brought about by its aftermath. To avoid any confounding effects in our findings driven by this unstable period, we selected the steadier 1990-1998 years to conduct our main analysis. We use the latter period (1999-2004), however, to assess the robustness of our results and report on it later in the paper.

$$
* * * \text { Insert Figure } 1 \text { about Here*** }
$$

Data on acquisitions are drawn from the Securities Data Corporation's (SDC) Platinum database. Our sampling universe consists of all high-tech acquisitions by US public firms in the period 1990-1998. No restrictions were placed on the trading status of the target firms, which allows us to include both public and private targets (as classified by SDC) in the study. In all cases, the acquirer had to obtain a majority of the target's equity $(50.1 \%)$ for the transaction to be included in the sample.

To ensure that all acquisitions came from knowledge-intensive industries, target firms were chosen from high-tech manufacturing and services sectors. Following prior studies (Hagedoorn and Duysters 2002), we sampled from the following SIC codes: (i) in the manufacturing sector: Drugs and Medicines (SIC 2833-2836), Computers and Office Equipment (3571-3579), Electrical Equipment (36123652), Communications Equipment (3661-3699), Aerospace and Aircraft (3721, 3724, 3728, 3761, 3764, 3769), Measuring, Photo Equipment and Clocks (3821-3899) and (ii) in the services sector: Computer Programming, Data Processing etc. (737X), Engineering Services (8711), and R\&D and Testing Services $(873 X)$.

We started with a total of 8,647 acquisitions completed during 1990-1998 that met the criteria listed above. For each deal, we determined whether the acquirer and target had partnered to form an alliance at any point before the acquisition. To do this, we obtained data from two sources. We began with alliances listed in SDC's Joint Ventures/Alliances database, and complemented the list by searching Lexis-Nexis and Factiva for news articles reporting collaborative relationships involving the acquirer and the target. To ensure that we captured all possible alliances, we searched for news that mentioned the names of the two companies in the same article. After carefully reading the articles, we identified 503 acquisitions in which the acquiring firm had a prior alliance with the target firm. The small percentage 
(around 6\%) of prior alliances relative to the 8,647 original acquisitions is consistent with the $7 \%$ found by Porrini (2004) in her sample of only public targets.

Since the focus of the study is to learn whether acquisitions preceded by alliances with the target perform better than those without prior alliances, we adopt a quasi-experimental research design (Cook and Campbell 1979), in which we compare M\&A performance of the treatment group (i.e. with a prior alliance) against that of a control group (i.e. without a prior alliance). While we are not able to randomly assign firms to form or not form alliances prior to merging, we attempt to make both groups as similar as possible on several characteristics except for whether they had a previous alliance. This matched sample methodology has been used in several research studies in accounting, finance, strategy, and marketing literatures (e.g., Bharadwaj 2000, Farrell and Whidbee 2000, Kalwani and Narayandas 1995, Kimbrough 2005, Singh and Harianto 1989).

To create the control group, we first divided our sample in two categories: international and domestic acquisitions. Then, following Singh and Harianto (1989), we constructed a control group of acquisitions in each category, in which the transaction occurred no more than a year before or after the reference acquisition, the acquiring firm had the same two-digit SIC code, was of comparable size (usually within $15 \%$ of the assets) to the focal acquirer in the reference group, but had no prior alliance with target. The matching process generated a usable set of 408 acquisitions, equally split between those with and without prior alliances. Thus, of 503 acquisitions with prior alliances in the original reference group, we had to discard 299 for which there was either no financial data available from Compustat, no stock price information from CRSP (Centre for Research in Security Prices), or for which we could not find a suitable match without a previous alliance.

We compared the 408 acquisitions included in the regression analysis with the $8,059(8,467-$ 408) that were not analyzed in this paper to assess the representativeness of our final sample. There were no differences between included and excluded acquisitions in the size of the acquirer (total assets), the likelihood of acquiring a foreign or publicly listed target, or the number of payment types used in the transaction. The acquisitions in the sample however were more likely to be between firms in unrelated 
industries $(\mathrm{p}<0.01$ from a two-sided t-test), to involve a higher price paid for the target $(\mathrm{p}<0.01)$, to occur in later years $(\mathrm{p}<0.01)$, and to include acquirers from the software industry $(\mathrm{p}<0.01)$. In contrast, acquirers in our analysis were less likely to come from the banking and insurance or from the educational and medical services industries $(\mathrm{p}<0.01)$.

These differences suggest some important boundary conditions for our results, namely that they are more likely to hold for unrelated acquisitions, for high-priced acquisitions, and for those in later years, the latter reflecting the increased importance placed on knowledge in the economy. The bulk of the industry groups included in the sample (viz. light manufacturing, heavy manufacturing, transportation and communications, and other services) are equally represented in the included and excluded sets, suggesting that the results generalize to them. In contrast, the results may not apply as fully to the banking, educational, insurance and medical services industries.

\section{Dependent Variable}

Acquisition performance. The dependent variable, acquisition performance, is captured in the acquirer's stock price reaction to the acquisition, as measured by the cumulative abnormal return (CAR) over a specific window surrounding the event announcement. While the benefits accruing to an acquirer from an acquisition can also be captured through accounting measures of performance (such as ROA), there are several advantages from using abnormal returns in our case. Abnormal returns allow us to directly trace performance to each specific acquisition because they capture the stock price reaction to a specific acquisition for a specific period surrounding its announcement. In contrast, accounting performance can only be measured in the reporting period after the acquisition is finalized. This raises a challenge because little intuition or theory exists to guide researchers in selecting precisely when to measure accounting performance after the acquisition. Even if it were possible to choose the optimal measurement moment, it is not possible to know if the observed performance driven by a specific acquisition or by a host of other events that occurred between the date of the acquisition announcement and the calculation of accounting numbers by the firm—such as other acquisitions, external shocks, product releases, personnel changes 
and so on. As a voluminous literature in financial economics suggests, stock price reactions to events reflect expectations of future performance (Malkiel 2003 presents a useful review). Importantly, research has shown that stock market reactions to acquisition announcements correlate well with subsequent performance of acquisitions (Healy et al. 1992, Sirower 1997). For example, Kaplan and Weisbach (1992) show that abnormal returns are good predictors of whether targets will be subsequently divested. While this market-based measure of performance has been challenged (Malkiel 2003), abnormal returns are a common, well-established measure of acquisition performance in strategy and finance (Bradley et al. 1988; Singh and Montgomery 1987).

Abnormal returns are calculated using residual analysis of the market model (Fama et al. 1969). Based on the acquisition announcement date, we set the event date at $t=0$. We then estimated the baseline market model for the 241-day period [-260, -20] using the formula: $r_{i t}=\alpha_{i}+\beta_{i} r_{m t}+\varepsilon_{i t}$, where $r_{i t}$ is the common stock return of firm $i$ on day $t, r_{m t}$ is the corresponding daily market return on the CRSP valueweighted index, $\alpha_{i}$ and $\beta_{i}$ are firm-specific parameters and $\varepsilon_{i t}$ is the error term. The estimates obtained from the market model were then used to predict returns for each acquiring firm through the formula: $\hat{r}_{i t}$ $=\hat{\alpha}_{i}+\hat{\beta}_{i} r_{m t}$, where $\hat{r}_{i t}$ is the predicted return and $\hat{\alpha}_{i}$ and $\hat{\beta}_{i}$ are the model estimates. The daily firmlevel abnormal returns were calculated as: $\hat{\varepsilon}_{i t}=r_{i t}-\hat{\mathrm{r}}_{i t}$. Finally, the cumulative abnormal return of firm $i$ during the event window period was calculated using the formula: $C A R_{i}=\sum_{t} \hat{\varepsilon}_{i t}$. We obtained returns over several short and medium time windows surrounding the acquisition announcement, including [-1,0], $[-1,1],[-5,0],[-5,1],[-5,5],[-10,0],[-10,10],[-15,0]$, and $[-15,15]$. Our findings are stable throughout all the windows, which we report in more detail below. For ease of presentation, we report our findings using the 11-day period $[-5,5]$. In a supplementary analysis, we also discuss findings for long event windows ranging between 36 to 60 months. 


\section{Independent Variables}

Prior alliance with target. We created the binary variable Prior Alliance, coded as 1 if the acquirer had prior alliance with target preceding the acquisition, and 0 otherwise. All the alliances in this study represent relationships in which the firms reached a formal agreement to exchange or commit resources. Also, if the acquirer had more than one prior alliance with the target, the earliest alliance between the partners is chosen as the focal alliance.

Prior international alliance. The binary variable Foreign Target is coded as 1 if the acquirer had prior alliance with an international firm preceding the acquisition, and 0 otherwise. Since all the acquirers in our study are headquartered in the US, international targets consist of non-US companies.

Alliance Strength. We identified five types of prior alliances in our study: R\&D, marketing, supplier, licensing, and equity only. We determined the type of alliance through a text analysis of the press release announcing the formation of the partnership, which contain clear statements of the purpose of the alliance and brief descriptions of the activities involved (see Appendix for examples). We categorized alliances into one of the five types only if the press release was unambiguous about the purpose of the relationship. In instances where the firms had more than one type of alliance, we coded the alliance type that was strongest in terms of interaction between the alliance partners.

We measure alliance strength based on the opportunities each tie creates for partner-specific learning. Prior research suggests that relationships formed to generate new knowledge, products, and unique combinations of each partner's capabilities involve the highest levels of interaction (Nohria and Garcia-Pont 1991). Scholars generally agree that R\&D partnerships fit such a description (e.g. Anand and Khanna 2000a). Our search of alliance announcements revealed that marketing agreements also involved intense collaboration based on co-commercialization of products in multiple markets, and that they often were accompanied by product development tasks. Notice from the Appendix, for example, that the marketing alliance between HP and Verifone involved "collaborative activities in other areas [besides joint selling]," the participation of a "multitalented team," and the "uniting of efforts across the board-in marketing, sales, and research." We note that the marketing alliances in our sample go beyond simple 
distribution agreements — which other research has rightly classified as weak (Contractor and Lorange 1988). Thus, both R\&D and marketing alliances require high resource commitments from partners, mutual trust, interdependence and learning through joint problem solving; consequently we classify them together as the strongest type.

We consider supplier alliances as the second strongest because the buyer and supplier often collaborate to solve problems and share quality and productivity benefits. Monczka et al. (1998) find that a successful supplier alliances exhibit characteristics that include "trust and coordination, interdependence, information quality and participation, information sharing, joint problem solving, avoiding the use of severe conflict resolution tactics" (p. 553). However, supplier alliances do not involve the co-development of knowledge and products to the same extent as marketing or R\&D ties.

Licensing alliances are weaker than supplier relations because they involve well-defined transfers of property rights (Mowery et al. 1996). The contract between the firms is clear and relatively unambiguous, with well-specified clauses and thus more easily enforceable (Anand and Khanna 2000b). Accordingly, licensing agreements require fewer resource commitments, less interdependence, and less joint problem solving by partners than do stronger relationships. Anand and Khanna's (2000a) finding that learning effects are stronger in the case of research joint ventures than of licensing contracts supports our reasoning. Equity-only relationships represent the weakest forms of alliances we found in the sample. We note that what we call equity-only ties are not equity joint ventures in which partners set up a separate legal entity in which both firms own a share and also tend to collaborate actively. Instead, as the text in the Appendix indicates, these are much more passive investments with the goal of obtaining partial control and sometimes voting rights.

According to the foregoing discussion, we created the variable Prior Alliance Strength in which we assigned each kind of tie an increasing strength score -1 for equity-only, 2 for licensing, 3 for supplier, and 4 for marketing or R\&D. In robustness checks, we modified Prior Alliance Strength by creating a five-point scale in which marketing or $R \& D$ ties received the highest rating. Moreover, we also 
created the indicator Prior Strong Alliance, which is coded as 1 for R\&D, marketing, and supplier ties, and $O$ otherwise. Our results led to the same conclusions regardless of the measure alliance strength used.

\section{Control Variables}

We control for several alternative factors that could affect the performance of acquisitions. A common acquisition characteristic studied by scholars is whether target and acquirer industries are related or not (Singh and Montgomery 1987). To account for relatedness, we include the variable Related Acquisition, coded as 1 if the target and acquirer primarily operate in the same industry (measured through the two-digit SIC code), and 0 otherwise. Further, the complexity of the acquisition transaction could itself affect its performance because more complex transactions may indicate difficulty in determining the value of the target. We control for this through the variable Considerations, a count of the number of payment types (considerations) offered for the target firm, such as cash, stock, and so on.

We include two important characteristics of the acquiring firm that could affect performance. We control for the acquirer's size through the variable Acquirer Total Assets. We also include the variable Acquisition Experience, measured as the number of all acquisitions completed by the acquirer in the five years preceding the observed acquisition in our sample (Hayward 2002). While acquisition experience is not a direct measure of acquisition prowess, it seems reasonable to expect a strong positive correlation between number of previous acquisitions and acquisition capabilities. We also measured this variable for several other time periods, ranging from three to ten years prior to the observed acquisition, and our findings remain unchanged.

Characteristics of the target firm should also influence acquisition outcomes. We mentioned in our theory that international strategies carry with them an inherent liability of foreignness (Zaheer, 1995). Thus, foreign targets are particularly difficult to evaluate and integrate. We control for this possibility through the indicator Foreign Target, coded as 1 if the target firm not from the US and 0 otherwise. We note that this variable overlaps with the indicator of whether the prior alliance was internationalhowever, there are international acquisitions without prior alliances in our study as well. One of the 
virtues of our sample is that it includes both public and private target firms. While this enhances the generalizability of our findings, it could be that acquiring private firms is more profitable than acquiring public ones. We thus include the indicator Public Target, coded as 1 if the target is publicly listed, and $O$ otherwise.

Finally, we account for target industry and time period effects that could affect the findings. We include indicators for five broad industry groups — light manufacturing, heavy manufacturing, transportation and communications, software and services, and other services. To control for acquisition performance driven solely by timing issues, we include separate dummy variables for each year in the sample, with the first year (1990) being the reference period. For clarity of presentation, our tables do not show coefficient estimates for the industry and year indicators, but they are included in every model.

\section{Model}

We test our first hypothesis by regressing CARi on Prior Alliance, as represented by the following equation:

$$
C A R_{i}=\beta_{0}+\beta_{1} * \text { Prior Alliance }{ }_{i}+\beta_{2} * \text { Controls }+\varepsilon_{i} .
$$

The argument behind $\mathrm{H} 1$ is that forming an alliance before acquiring a target can be a superior acquisition strategy in knowledge-intensive industries. If firms are aware of the advantages of forming prior alliances, then our findings could exhibit endogeneity driven by selection bias - that is, superior firms may intentionally select to engage in prior alliances at a higher rate than inferior firms. Thus, the OLS coefficient estimates of Prior Alliance could be biased upward due to self-selection. To account for this possibility, we estimated equation (1) using Maddala's (1983) treatment-effects estimator, which accounts for the potential endogeneity of Prior Alliance. This two-step estimator first models the probability of selecting the 'treatment' (in our case, equation (2) below) through a probit model, and then accounts for that probability in a second-stage least-squares model (equation (1) above). Applied to our scenario, the first-stage equation is as follows:

$$
\text { Prior Alliance }_{i}=\beta_{0}+\beta_{1} * \text { Alliance Experience }{ }_{i}+\beta_{2} * X_{i}+\mu_{\mathrm{i}} .
$$


The variable Alliance Experience is a predictor of the probability of forming Prior Alliance that is not included in the second-stage equation (1). A voluminous literature on alliance formation finds that previous alliance experience is positively related to subsequent alliance formation (e.g. Gulati 1995, Gulati and Gargiulo 1999). Alliance experience is measured as the number of alliances formed during and extended time window before the observed alliance in our sample. We used different experience windows, ranging from three to ten years, and our findings were unaltered. The term $X_{i}$ contains other predictors of alliance formation that are also included in our second stage equation-Acquirer Total Assets, Related Alliance (i.e. same two-digit SIC code), Public Target, and dummies for each year and target industry group. From this analysis, we found that alliance experience was a good predictor of alliance formation $(p<0.01)$ in the first stage equation. However, we tested for and found that Maddala's (1983) $\lambda$ parameter is far from significant $(p=0.87)$, indicating that the error terms of the two equations are uncorrelated, and thus suggesting that selection bias does not exist in our sample.

To test our other three hypotheses, we restrict our sample to a subset of observations that have formed prior alliances ( $\mathrm{H} 3$ and $\mathrm{H} 4)$, or that have engaged in foreign acquisitions (H2). For example, to test H3 and H4 we restrict Prior Alliance to equal 1 , and given this condition estimate the following equation:

$\left(C A R_{i} \mid\right.$ Prior Alliance $\left.=1\right)=\beta_{0}+\beta_{1} *$ Prior Alliance Strength $h_{i}+\beta_{2} *$ Foreign Target ${ }_{i}+\beta_{3} *$ Controls $+\varepsilon_{\mathrm{i}} .(3)$

We expect the coefficients of Prior Alliance Strength and Foreign Target to be positive and significant in support of $\mathrm{H} 4$ and $\mathrm{H} 3$, respectively. While in this case we are only looking within the subset of acquisitions that had prior alliances, it may be necessary to account for self-selection into this subset for the same reasons just discussed. To explore whether endogeneity is a concern, we estimated equation (3) via Heckman's (1979) selection model, which also predicts the likelihood of forming Prior Alliance in a first-stage regression (in our case, via equation (2)). In the second stage, however, equation (3) is estimated only for the subset of acquisitions for which Prior Alliance $=1$, but taking into account the probability of forming a prior alliance. As in the treatment model, Alliance Experience is a significant predictor of alliance formation $(p<0.05)$, but the likelihood-ratio (LR) test of independent equations 
failed to reject the null hypothesis that selection bias does not exist in our sample $(p=0.44)$. (A similar reasoning applies to $\mathrm{H} 2$, where we restrict the sample to only foreign acquisitions, but we omit the details because the solution is analogous).

Given that self-selection bias is not a concern in our sample, we opted to use the traditional OLS estimator to test our hypotheses via equations (1) and (3). However, we do so with the confidence that our coefficient estimates are not plagued by endogeneity concerns. We note that our findings regarding the hypotheses are the same if we use OLS than if we use Maddala's (1983) and Heckman's (1979) controls for self-selection, which further suggests that the OLS estimator is unbiased in this case. We also refined our regression model to account for the non-independence of observations. Given that some acquirers are repeated in our sample, it is likely that their acquisitions are not independent of each other, which may lead to improper standard error estimates. To correct for this, we estimate all standard errors in the regressions using the 'sandwich' estimator (Huber 1967), which also accounts for heteroskedasticity.

\section{Results}

Table 1 presents a detailed summary of daily and cumulative abnormal returns. Panel A displays the average daily abnormal return for all firms in the sample and provides a sense for the fluctuation of returns surrounding acquisition announcements. Panel B summarizes the cumulative abnormal returns for several windows around the announcement day, along with various tests of whether the returns are different from the average market return leading up to the event. Consistent with our primary interest in explaining the cross sectional variation in our measure of acquisition performance, Panel $\mathrm{C}$ presents the average returns for the $[-5,5]$ window — which we use in our regression analysis - for various subsamples of interest. We also plotted the daily abnormal returns for the same subgroups in Figures 2a through 2c. Counter to our expectations for $\mathrm{H} 1$, Panel $\mathrm{C}$ of Table 1 reveals that acquisitions without prior alliances exhibit higher average returns than those with prior alliances. Figure 2 a further shows that the daily returns closely track each other for the groups with and without prior ties. Consistent with H3, the subgroup with previous foreign alliances shows a higher average return than the group with domestic 
prior alliances - a fact visually confirmed by Figure 2b. As expected from H4, acquisitions with stronger prior alliances $(\mathrm{R} \& \mathrm{D}$, marketing, or supplier) show higher average returns over the $[-5,5]$ window than those preceded by weaker ties (licensing or equity-only) in both Panel C of Figure 1 and in Figure 2c. We now turn to our regression analysis, in which we confirm the initial evidence provided by the preceding descriptive analysis.

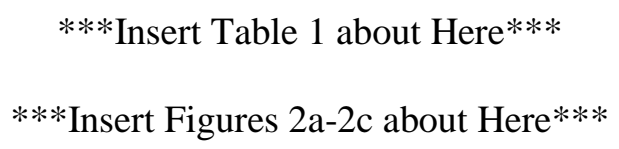

Table 2 shows summary statistics and correlations, and Table 3 presents the results from the regressions. Model 1 includes the control variables, of which only Considerations is marginally significant $(p<0.10)$ and positive. We test our first hypothesis in Model 2 by including Prior Alliance in the regression. Contrary to our expectations, the effect of having an alliance before the acquisition is not significant, thus failing to provide support for H1. We next turn to our second hypothesis, which predicts that for the subset of international acquisitions, those involving prior alliances will exhibit better performance than those without such alliances. To test this, we restrict the sample in Model 3 only to international acquisitions, which brings the sample size down to 87 observations (note that the coefficient for Foreign Target drops out of this model). In support of H2, we find that Prior Alliance is positive and significant $(p<0.05)$. In international settings, acquirers with a prior alliance gain an additional $6.6 \%$ increase in abnormal stock returns relative to acquirers without a prior alliance.

\section{***Insert Table 2 about Here***}

The third hypothesis provides additional nuance to the international context, by predicting that within the set of firms with prior alliances (i.e. Prior Alliance $=1$ ), foreign acquisitions will perform better than domestic ones. To test this, we limit the sample to acquisitions with prior alliances, and find that the coefficient of Foreign Target is positive and significant $(p<0.01)$ in support of H3. International acquisitions with prior alliances exhibit abnormal returns that are $5.7 \%$ higher than domestic acquisitions with prior alliances. Model 5 tests our final hypothesis, which predicts that engaging in stronger alliances prior to acquisition leads to superior M\&A performance than engaging in prior weaker alliances before 
the acquisition. In support of H4, we find that Prior Alliance Strength is positive and significant ( $p<$ 0.05 ), providing a $1.1 \%$ improvement in abnormal returns for every additional level of strength—thus, $\mathrm{R} \& \mathrm{D}$ and marketing ties (strength $=4$ ) produce returns $3.3 \%$ higher than equity only relationships (strength $=1)$. We note that Foreign Target remains significant in this model $(p<0.01)$ as H3 predicts.

$$
\text { ***Insert Table } 3 \text { about Here*** }
$$

Supplementary Analyses. We conducted a number of supplementary analyses and robustness checks to further bolster confidence in our findings. As mentioned previously, we used multiple event windows to measure abnormal returns (see the description of the dependent variable for a detailed list). Our findings are generally stable when using these alternative windows. H1 is not supported as in our main analysis, while $\mathrm{H} 2-\mathrm{H} 4$ are in half or more of the alternative time frames. In addition, we created an interaction between Prior Strong Alliance and Foreign Target with the objective of assessing whether the combination of these conditions, which per our arguments help reduce information asymmetry, creates an additional acquisition performance benefit over and above the main effects of those two conditions separately. The interaction was marginally significant $(p<0.10)$.

Finally, while we make a case above for selecting the 1990-1998 years as the most appropriate period for our analysis, we assessed whether our findings are affected by our choice of sampling period. First, we analyzed whether the hypotheses hold in the highly volatile 1999-2004 time frame. As before, we found no support for H1, suggesting that prior alliances per se did not improve acquisition performance. Also in line with our main analysis, prior international alliances ( $\mathrm{H} 2$ and $\mathrm{H} 3)$ were positively and significantly related to performance. Contrary to expectations, however, the effect of strong prior alliances on M\&A performance was not significant, though still positive. Second, in line with prior research identifying the early months of the year 2000 as the unraveling of the tech bubble (Uhlenbruck et al. 2006), we extended our sample until the end of both 1999 and 2000. In this case, the findings were entirely consistent with our primary analysis—-we found no support for H1, but did for H2-H4. 


\section{DISCUSSION}

In an effort to understand the conditions under which some acquirers earn superior returns for their stockholders, we identified prior alliances with targets as a possible mechanism to mitigate the ex ante and ex post problems of information asymmetry between knowledge acquirers and potential target firms. We invoke the concept of partner-specific absorptive capacity (Dyer and Singh, 1998) as implying a deep understanding of knowledge-intensive targets by potential acquirers which alleviates both pre- and postacquisition information asymmetry. We contribute to the literature by theorizing that partner-specific absorptive capacity is enhanced through prior alliances with targets and is particularly useful in ameliorating information asymmetry both in international acquisitions and when prior target alliances are stronger rather than weaker.

Our finding for H1 was contrary to our expectations: we found that prior target alliances did not significantly improve acquisition performance for knowledge acquisitions in general. This result is surprising, particularly in view of the strong theoretical arguments in its favor. It also goes against the findings of the limited prior empirical research on this issue by Porrini (2004), who did find a generally positive effect of prior target alliances on acquisition performance. However, the restricted acquisition data set in that study - which included only 31 prior alliances - as well as the reliance on ROA change, which can include a number of confounding influences, warrants further investigation. In contrast, research by Uhlenbruck et al. (2006) offers a precedent for the notion that no general effect exists for alliances prior to acquisitions, which suggests that the effect of prior alliances may be contingent on other factors, although these scholars do not investigate what the other factors may be.

One explanation for the lack of support for the first hypothesis may be that in fact no general benefit of knowledge acquisitions with prior target alliances exists, except under certain more specific conditions. Such a result would be consistent with the idea that in general, prior alliances, even in knowledge-intensive industries, do not offer a private information benefit because public information on the knowledge assets of high-tech targets is usually sufficient (captured by patents, FDA filings and the like). Alternatively, it could be that not all types of alliances are equally useful in helping acquirers assess 
knowledge assets. For example, a weak alliance by itself may not be sufficiently informative of the target's intangible knowledge assets, and it is only when alliances are strong that the acquirer is able to access the target's embedded information and knowledge.

Since total alliances include both strong and weak alliances, we investigated this possibility further by testing the effects on acquisition performance of weak alliances alone compared to not having a prior alliance at all. The results are interesting - we actually find that prior weak alliances exert a significant negative effect on acquisition performance relative to no prior alliance, which may reflect the fact that the cost of creating and sustaining weak alliances is higher than the private information benefit they provide prior to an acquisition. Thus, it appears that the negative effect of weak alliances is pulling down the effect of other types of prior alliances on acquisition performance compared to not having prior alliances before acquiring — resulting in no overall effect of prior alliances on acquisition performance. Our result on the negative effects of weak alliances relative to no alliances echoes recent work by Li et al. (2008) which finds that firms prefer to form new alliances with strangers rather than with weak ties.

As hypothesized, we did find a strong effect of prior alliances on international knowledge acquisitions. The effect is apparent both in international knowledge acquisitions following target alliances against international knowledge acquisitions without prior alliances (H2), as well as in international knowledge acquisitions with prior alliances relative to domestic knowledge acquisitions with prior alliances (H3). These results are strongly supportive of our thesis which, building on the international management literature, argued that the greater information asymmetry in international contexts arising the 'liability of foreignness' yields a positive effect on acquisition announcement because of the greater potential and need for learning via partner-specific absorptive capacity through prior alliances. In other words, the market recognizes the greater possibilities of alliance learning and the reduction in information asymmetry when the target is an international one. From the controls, it is noteworthy that domestic vs. foreign acquisitions by themselves do not vary in performance, but differ only when international acquisitions are preceded by an alliance between the target and the acquirerwhich makes a more nuanced case for the existence of partner-specific absorptive capacity. The data 
suggest that rather than international strategies per se being valuable, they must be executed with a deep awareness of the need for partner-specific learning and coupled with a prior alliance that enhances understanding about the international target.

Our final set of results is also noteworthy: as expected, we find that stronger prior alliances yield superior acquisition performance than weaker prior alliances. We defined alliance strength in terms of the intensity of interaction between the potential target and acquirer firms, indicating that acquisition performance improves when greater partner-specific learning has occurred via the more intimate and intense interaction arising from stronger alliances. This theoretical mechanism is further bolstered when we consider the results for the interaction of prior international alliances with strong alliances, which yield a positive, though marginally significant, effect. This finding suggests that in cases which combine high information asymmetry and intense interaction with the potential target, strong alliances work to enhance partner-specific absorptive capacity and reduce information asymmetry to an even greater extent than weaker forms of alliances in domestic settings. The combination of findings regarding international vs. domestic (H2-H3) and strong vs. weak alliances (H4) provide compelling, though indirect, evidence that partner-specific absorptive capacity may be the mechanism behind our observed M\&A performance.

In order to conduct sensitivity tests over a more recent time frame, albeit one which exhibits high volatility in total acquisition and alliance activity, we tested our hypotheses during the period 1999-2004. We find that the performance advantages of prior international alliances $(\mathrm{H} 2-\mathrm{H} 3)$ still accrue to acquirers $(p<0.01)$, while the benefits of prior strong alliances relative to weak ones (H4) are not statistically significant. Considering the evidence from Figure 1 that this period clearly exhibited high volatility, we are cautious when interpreting these findings. One reason for these findings could be that the proportion of weak alliances in the 1999-2004 data is only $25 \%$, compared to $47 \%$ in the 1990-1998 sample - thus, the variance in weak alliances may be too limited to pick up an effect. More substantively, this suggests that firms are increasingly gravitating to stronger alliances over time, perhaps recognizing the learning benefits derived from greater interaction intensity between two firms. Yet another interpretation might be that in lean times (such as the post-2001 years), firms are much stricter about the risks involved in 
acquisitions and go for safer bets in which the benefits of prior alliances, even if strong, do not emerge. On the other hand, with international acquisitions, the essential asymmetry in the context-specific knowledge stays in place, and thus the risk cannot be easily mitigated.

Our study contributes to the literature in several ways. First, it focuses on the broad conditions under which acquiring firms create value for their shareholders, in our case the existence of certain types of prior alliances before acquisitions. While prior studies mostly emphasize that almost two-thirds of all acquisitions fail, one third of acquisitions clearly succeed. Thus, what makes an acquisition a failure or success is an important research issue in organization and management literatures. Second, not only does our study identify prior alliances with target as a potentially useful pre-acquisition strategy, but also it goes further to identify still more nuanced contingencies that make this strategy valuable — such as the type of target, whether international or domestic, and the type of alliance, whether strong or weak. Finally, our results, while not conclusive, support the explanation that the reduction in information asymmetry, accomplished through increased partner-specific absorptive capacity, between the potential acquirer and target firms may be the causal mechanism that accounts for the results. By presenting this reasoning we offer a credible explanation for the typically poor performance of acquisitions and highlight one potential solution to soften the information asymmetry pitfalls inherent in them.

Our study has limitations that future research may address. While we present compelling indirect evidence of partner-specific learning and reduction in information asymmetry, we do not directly test for learning as an intermediate step between alliance formation and acquisition performance. Future research may attempt to more directly relate the outcomes to the theorized intervening processes, such as learning or trust. A promising direction for future research would be to measure the extent of direct knowledge transfer occurring after the formation of the alliance but before the acquisition. A possible approach would be to capture the pattern of patent cross-citations in setting where patents are central to the knowledge-creation and learning process (such as the biochemistry industry). While this approach would have helped us provide more direct evidence of learning in this study, we note that a large number of firms in our sample do not rely patents as primary conduits of knowledge creation. 
Another extension of our research would be to capture the different motivations for the acquisitions themselves. Scholars have pointed out that M\&A are conducted to serve many different purposes, such as learning, market share, eliminating competition (Bower 2001), or international expansion. These acquisition purposes could interact with the motivations for alliances formed prior to the acquisition. Scholars could explore whether different performance outcomes more directly associated with the acquisition motivation, such as market share or industry consolidation. While one of the major virtues of our dataset is that we also include private firms, obtaining good data on these private acquisition targets is difficult. Ideally, we would have liked to include additional controls— such as the relative size of the acquirer and target, stock premiums and other market-based measures - in our regressions, but the unavailability of quality data on private targets precluded the inclusion of these variables.

\section{Concluding Remarks}

While considerable research on mergers and acquisitions focuses on the conditions under which acquisitions create value, acquisitions of knowledge-intensive targets present special challenges arising from the difficulties of assessing knowledge assets. Thus, strategies that alleviate problems of information asymmetry, such as forming alliances prior to acquisitions, are particularly valuable for acquirers. Our research contributes to the literature by theorizing about how alliances create partnerspecific absorptive capacity which contributes to a reduction in information asymmetry and consequently higher acquisition performance in knowledge-based industries. Our findings indicate that while in general prior alliances do not aid acquisition performance, they are beneficial under certain conditionsspecifically when information asymmetry is elevated in international contexts, and when prior alliances require intense partner-specific learning. Together, the results support our thesis that partner-specific absorptive capacity may be at work and suggest that given certain contingencies high-tech acquisitions can indeed produce economic value. 


\section{REFERENCES}

Akerlof, G. A. 1970. The market for lemons: Quality for uncertainty and the market mechanism. Quarterly J. Economics. 84 488-500.

Anand, B., T. Khanna, 2000a. Do firms learn to create value? The case of alliances. Strategic Management J. 21 295-315.

. 2000b. The structure of licensing contract. J. Industrial Economics. 48 103-135.

Andrade, G., M. Mitchell, E. Stafford. 2001. New evidence and perspectives on mergers. J. Economic Perspectives. 15(2) 103-120.

Arino, A., de la Torres. 1998. Learning from failure: Towards an evolutionary model of collaborative ventures. Organ. Sci. 9 306-325.

Arrow, K. J. 1974. The Limits of Organization. Norton, New York.

Badaracco, J. 1991. The Knowledge Link. Harvard Business School Press, Boston, MA.

Balakrishnan, S., M. P. Koza. 1993. Information asymmetry, adverse selection and joint-ventures: Theory and evidence. J. Economic Behav. \& Organ. 20(1) 99-117.

Barney, J. B. 1988. Returns to bidding firms in mergers and acquisitions: Reconsidering the relatedness hypothesis. Strategic Management J. 971-78.

Barney, J. 1991. Firm resources and sustained competitive advantage. J. Management, 17(1) 99-120.

Bharadwaj, A. 2000. A resource-based perspective on information technology capability and firm performance: An empirical investigation. MIS Quarterly. 24(1) 169-196.

Bleeke, J., D. Ernst. (eds.). 1993. Collaborating to Compete: Using Strategic Alliances and Acquisitions in the Global Marketplace. Wiley, New York.

Bower, J. L. (2001). Not all M\&As are alike--and that matters. Harvard Business Review, 79(3), 92-101.

Bowman, E. H., D. Hurry. 1993. Strategy through the Option Lens: An Integrated View of Resource Investments and the Incremental-Choice Process. Acad. Management Rev. 18 760-782.

Bradley, M., A. Desai, E. Kim. 1988. Synergistic gains from corporate acquisitions and their division between the stockholders of target and acquiring firms. J. Financial Economics. 20(11) 987-1018.

Burt, R. 1992. The social structure of competition. N. Nohria and R. Eccles, eds. Networks and Organizations: Structure, form and action. Harvard University Press, Boston, MA. 57-91.

Capron, L., P. Dussauge, W. Mitchell. 1998. Resource redeployment following horizontal acquisitions in Europe and North America, 1988-1992. Strategic Management J. 19 631-661. 
794.

, N. Pistre. 2002. When do acquirers earn abnormal returns? Strategic Management J. 23 781-

Chen, S., J. F. Hennart. 2004. A hostage theory of joint ventures: Why do Japanese investors choose partial over full acquisitions to enter the United States? J. Business Research. 57 1126-1134.

Chi, T. 1994. Trading in strategic resources: Necessary conditions, transaction cost problems, and choice of exchange structure. Strategic Management J. 15 271-290.

Coff, R., W. 1999. How buyers cope with uncertainty when acquiring firms in knowledge-intensive industries: Caveat emptor. Organ. Sci. 10(2) 144-161.

Cohen, M. D., D. Levinthal. 1990. Absorptive capacity: A new perspective on learning and innovation. Admin. Sci. Quart. 35 128-152.

Contractor, F. J., \& Lorange, P. (1988). Cooperative Strategies in International Business: Joint Ventures and Technology Partnerships Between Firms. Lexington, MA: Lexington Books.

Cook, T. D., D. T. Campbell. 1979. Quasi-Experimentation: Design \& Analysis Issues for Field Settings. Houghton Mifflin Company, Boston.

Donaldson, B., T. Toole. 2000. Classifying relationship structures: Relationship strength in industrial markets. J. Business \& Industrial Marketing. 15(7) 491-506.

Doukas, J., N. Travlos. 1988. The effect of corporate multinationalism on shareholders' wealth: Evidence from international acquisitions. J. Finance. XLIII(5) 1161-1175.

Dyer, J., H. Singh. 1998. The relational view : Cooperative strategy and sources of interorganizational competitive advantage. Acad. Management Rev. 23 660-679.

Fama, E., L. Fisher, M. Jensen, R. Roll. 1969. The adjustment of stock prices to new information. International Economic Rev. 10 1-21.

Farrell, K., D. A. Whidbee. 2000. The consequences of forced CEO succession for outside directors. $J$. Business. 73(4) 597-627

Finkelstein, S., Y. S. Choi, S. T. Tran. 1998. Cisco Systems Inc. and the networking equipment industry. The Amos Tuck School Dartmouth College Case Studies.

Garette, B., P. Dussauge. 2000. Alliances vs. acquisitions: Choosing the right option. European Management J. 18 63-69.

Giliberto, M. S., N. P. Varaiya. 1989. The winner's curse and bidder competition in acquisitions : Evidence from failed bank auctions. J. of Finance. 44(1) 59-75.

Graebner, M. E. 2004. Momentum and serendipity: How acquired leaders create value in the integration of technology firms. Strategic Management J. 25(8-9) 751-777.

Granovetter, M. S. (1973). The strength of weak ties. American J. Sociology, 78(6), 1360. 
Granovetter, M. 1985. Economic Action and Social Structure: The Problem of Embeddedness. American J. Sociology. 91(3) 481-510.

Gulati, R. 1995. Does familiarity breed trust? The implications of repeated ties for contractual choice in alliances. Acad. Management J. 38 85-112.

1999. Network location and learning : The influence of network resources and firm capabilities on alliance formation. Strategic Management J. 20 397-420.

Gulati, R., \& Gargiulo, M. (1999). Where do interorganizational networks come from? American J. Soc., 104(5), 439-93.

Gulati, R., Lavie, D., \& Singh, H. (2008). The nature of partnering experience and the gains from alliances. Strategic Management J., forthcoming.

Hagedoorn, J., G. Duysters. 2002. External sources of innovative capabilities: The preference for strategic alliance or mergers. J. Management Studies. 39(2) 177-188.

Hamel, G., Doz, Y. L., \& Prahalad, C. K. (1989). Collaborate with your competitors and win. Harvard Business Review, 67(1), 133-139.

Haspeslagh, P., D. Jemison. 1991. Managing Acquisitions: Creating Value through Corporate Renewal. Free Press, New York.

Hayward, M. L. A. 2002.When do firms learn from their acquisition experience? Evidence from 1990 to 1995. Strategic Management J. 23 21-39

Healy, P., K. Palepu, R. Ruback. 1992. Does corporate performance improve after mergers? J. Financial Economics. 31 135-175.

Heckman, J. (1979). Sample selection bias as a specification error. Econometrica, 47(1), 153-161.

Hennart, J. F. 1988. A transaction cost theory of equity joint ventures. Strategic Management J. 9 361374.

S. Reddy. 1997. The choice between mergers/acquisitions and joint ventures: The case of Japanese investors in the United States. Strategic Management J. 18 1-12.

. 2000. Digestibility and asymmetric information in the choice between acquisitions and joint ventures: Where's the beef? Strategic Management J. 21 191-193.

Hitt, M., J. Harrison, R. D. Ireland. 2001. Mergers and Acquisitions: A Guide to Creating Value for Stakeholders. Oxford University Press, New York.

Hoang, H., \& Rothaermel, F. T. (2005). The effect of general and partner-specific alliance experience on joint R\&D project performance. Acad. Management J., 48(2), 332-345.

Huber, P. J. (1967). The behavior of maximum likelihood estimates under nonstandard conditions. Proc. $5^{\text {th }}$ Berkeley Symposium in Mathematical Statistics, 1, 221-233. 
Hymer, S. H. (1960). The international operations of national firms, a study of direct foreign investment. MIT Press: Cambridge, MA.

Inkpen, A. 1998. Learning, knowledge acquisition, and strategic alliances. European Management J. 16 223-229.

Jemison, D. B., S. B. Sitkin. 1986. Corporate Acquisitions: A Process Perspective. Acad. Management Rev. 11145.

Jensen, M., R. Ruback. 1983. The market for corporate control : The scientific evidence. J. Financial Economics. 15-50.

Johanson, J., J. Vahlne. 1977. The internationalization process of the firm--A model of knowledge development and increasing foreign market commitments. J. International Bus. Stud. 8(1) 23-32.

Kale, P., H. Singh, H. Perlmutter. 2000. Learning and protection of proprietary assets in strategic alliances: Building relational capital. Strategic Management J. 21 217-237.

Kalwani, M., N. Narayandas. 1995. Long-term manufacturer-supplier relationships: Do they pay off for supplier firms? Journal of Marketing. 59(1) 1-17

Kaplan, S., M. Weisbach. 1992. The Success of Acquisitions: Evidence from Divestitures. J. Finance. 47(1) 107-138.

Khanna, T., R. Gulati, N. Nohria. 1998. The dynamics of learning alliances. Strategic Management J. 19 193-210.

Kimbrough, M. D. 2005. The effect of conference calls on analyst and market underreaction to earnings announcements. Accounting Rev. 80(1) 189-201.

Kogut, B. 1988. The stability of joint ventures : Reciprocity and competitive rivalry. J. Industrial Economics. 38 183-198. 1991. Joint ventures and the option to expand and acquire. Management Sci. 37(1) 19-33.

U. Zander. 1992. Knowledge of the firm, combinative capabilities, and the replication of technology. Organ. Sci. 3(3) 383-397.

Kostova, T., S. Zaheer. 1999. Organizational legitimacy under conditions of complexity:The case of the Multinational enterprise. Acad. Management Rev. 24 64-81.

Krishnan, H. A., Hitt, M. A., \& Park, D. 2007. Acquisition premiums, subsequent workforce reductions and post-acquisition performance. J. Management Studies, 44(5), 709-732.

Larson, A. (1992). Network dyads in entrepreneurial settings: A study of the governance of exchange relationships. Admin. Sci. Quarterly, 37(1)

Larsson, R., L. Bengtsson, K. Henriksson, J. Spartks. 1998. The interorganizational learning dilemma: Collective knowledge development in startegic alliances. Organ. Sci. 9 285-305. 
Li, D., Eden, L., Hitt, M. A., \& Ireland, R. D. 2008. Friends, acquaintances, or strangers? Partner selection in R\&D alliances. Acad. Management J., 51(2), 315-334.

Liebeskind, J. P. 1996. Knowledge, strategy and the theory of the firm. Strategic Management J. 17 (Winter special issue) 93-108.

Maddala, G. S. (1983). Limited-dependent and qualitative variables in econometrics Cambridge University Press.

Malkiel, B. G. (2003). The efficient market hypothesis and its critics. Journal of Economic Perspectives, 17(1), 59-82.

Markides, C., C. Ittner. 1994. Shareholder benefits from corporate international diversification: Evidence from U.S. international acquisitions. J. International Bus. Stud. 25(2) 343-366.

Marsden, P. 1990. Network data and measurement. Annual Rev. Sociology. 16 435-463.

Mergers \& Acquisitions. 1999. Snapshot Analysis. Mergers \& Acquisitions: The Dealermaker's J., 33(5), 49.

Monczka, R., K. Peterson, R. Handfield, G. Ragatz. 1998. Success factors in strategic supplier alliances: The buying company perspective. Decision Sci. 29(3) 553-573.

Mowery, D. C., J. E. Oxley, B. S. Silverman. 1996. Strategic alliances and interfirm knowledge transfer. Strategic Management J. 17 (Winter special issue) 187-221.

Nohria, N., C. Garcia-Pont. 1991. Global strategic linkages and industry structure. Strategic Management J. 12 105-124.

Nonaka, I. 1994. A dynamic theory of knowledge creation. Organ. Sci. 5(1) 14-37. , H. Takeuchi. 1995. The Knowledge Creating Company. Oxford University Press, New York. , \& von Krogh, G. 2009. Tacit Knowledge and Knowledge Conversion: Controversy and Advancement in Organizational Knowledge Creation Theory. Organ. Sci., 20(3) 635-652.

Polanyi, M. 1963. The Tacit Dimension. Peter Smith, Gloucester, MA.

Porrini, P. 2004. Can a previous alliance between an acquirer and a target affect acquisition performance? J. Management. 30(4) 545-562.

Powell, W. Neither market nor hierarchy: Network forms of organization. Research in Organizational Behavior, 12 295-336.

Puranam, P., Singh, H., \& Zollo, M. 2006. Organizing for innovation: Managing the coordinationautonomy dilemma in technology acquisitions. Acad. Management J., 49(2) 263-280.

, \& Chaudhuri, S. 2009. Integrating Acquired Capabilities: When Structural Integration Is (Un)necessary. Organ. Sci., 20(2) 313-328. 
Robson, M. J., Katsikeas, C. S., \& Bello, D. C. 2008. Drivers and Performance Outcomes of Trust in International Strategic Alliances: The Role of Organizational Complexity. Organ. Sci., 19(4) 647-665.

Rowley, T.B., Behrens, D., Krackhardt, D. Redundant governance structures: An analysis of structural and relational embeddedness in the steel and semiconductor industries. Strategic Management J., 21, 369386.

Sarkar, M., Aulakh, P. S., \& Madhok, A. 2009. Process Capabilities and Value Generation in Alliance Portfolios. Organ. Sci, 20(3) 583-600.

Singh, H., F. Harianto. 1989. Manager-board relationships, takeover risk, and the adoption of Golden Parachutes. Acad. Management J. 32(1) 7-24.

C. A. Montgomery. 1987. corporate acquisition strategies and economic performance. Strategic Management J. $8377-386$.

Sirower, M. 1997. The Synergy Trap : How Companies Lose the Acquisition Game. Free Press, New York.

Szulanski, G. 1996. Exploring internal stickiness: Impediments to the transfer of best practices within the firm. Strategic Management J. 17 27-43.

Teece, D. J. 1980. Economics of scope and the scope of the enterprise. J. Economic Behav. \& Organ. 1 223-369.

Uhlenbruck, K., Hitt, M. A., \& Semadeni, M. 2006. Market value effects of acquisitions involving internet firms: A resource-based analysis. Strategic Management J., 27(10) 899-913.

Uzzi, B. 1999. Embeddedness in the making of financial capital: How social relations and network benefit firms seeking financing. American Sociological Rev. 64 481-505.

Vanhaverbeke, W., G. Duysters, N. Noorderhaven. 2002. External technology sourcing through alliances or acquisitions : An analysis of the application specific integrated circuits industry. Organ. Sci. 13(6) 714733.

von Hippel, E. 1988. The Sources of Innovation. Oxford University Press, New York.

Walsh, J. P. 1988. Top management turnover following mergers and acquisitions. Strategic Management J., 9 173-183.

Williamson, O. 1985. The Economic Institutions of Capitalism. Free Press, New York.

Zaheer, A., B. McEvily, B., V. Perrone. 1998. Does trust matter? Exploring the effects of interorganizational and interpersonal trust on performance. Organ. Sci. 9 1-20.

Zaheer, S. 1995. Overcoming the liability of foreignness. Acad. Management J. 38 41-63.

Zollo, M., J. J. Reuer, H. Singh. 2002. Interorganizational routines and performance in strategic alliances. Organ. Sci. 13(3) 339-352. 
Figure 1

M\&A and Alliance Volume - 1990-2004

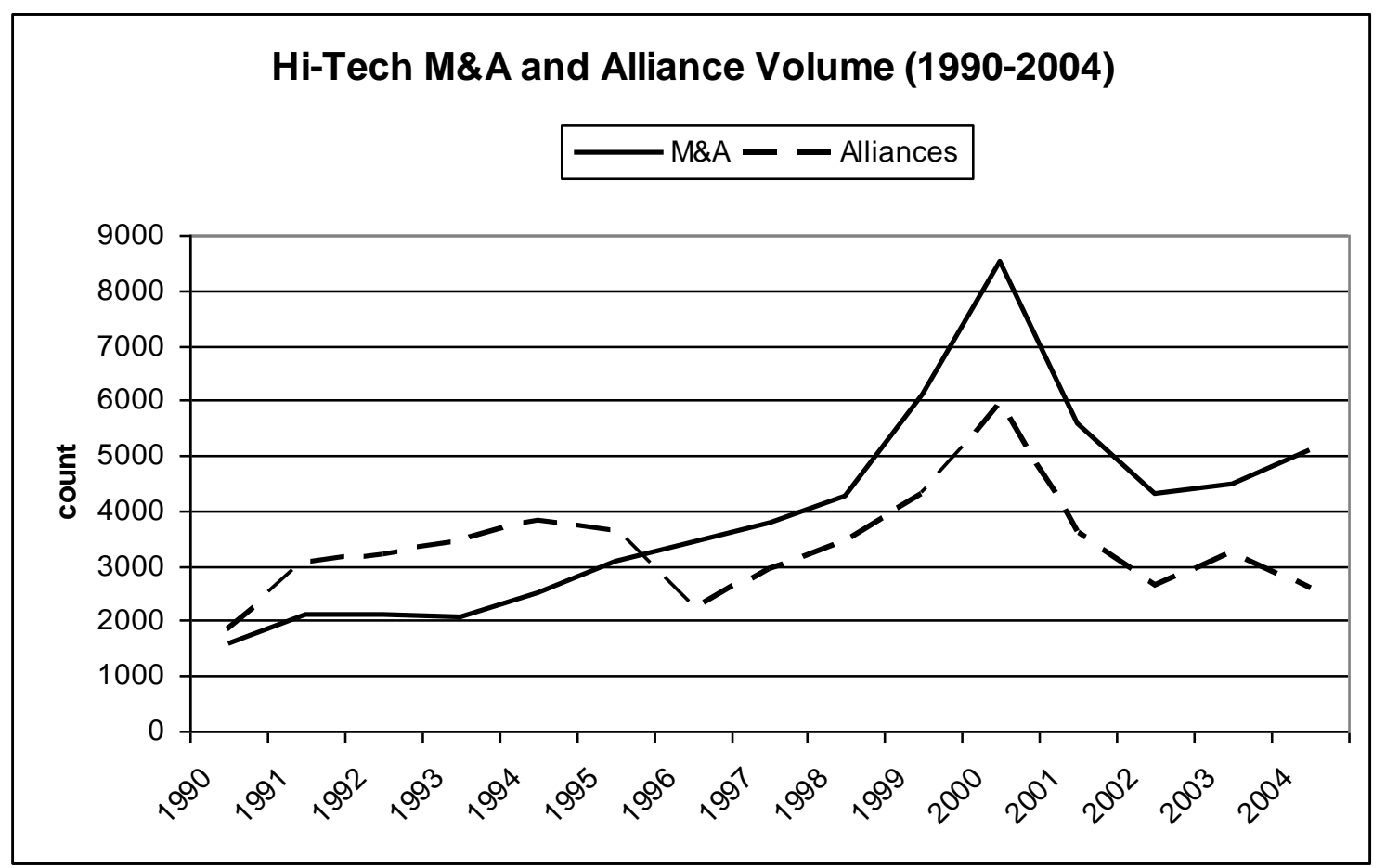

Figure 2a

Daily Abnormal Returns for Acquisitions with and without Prior Alliances

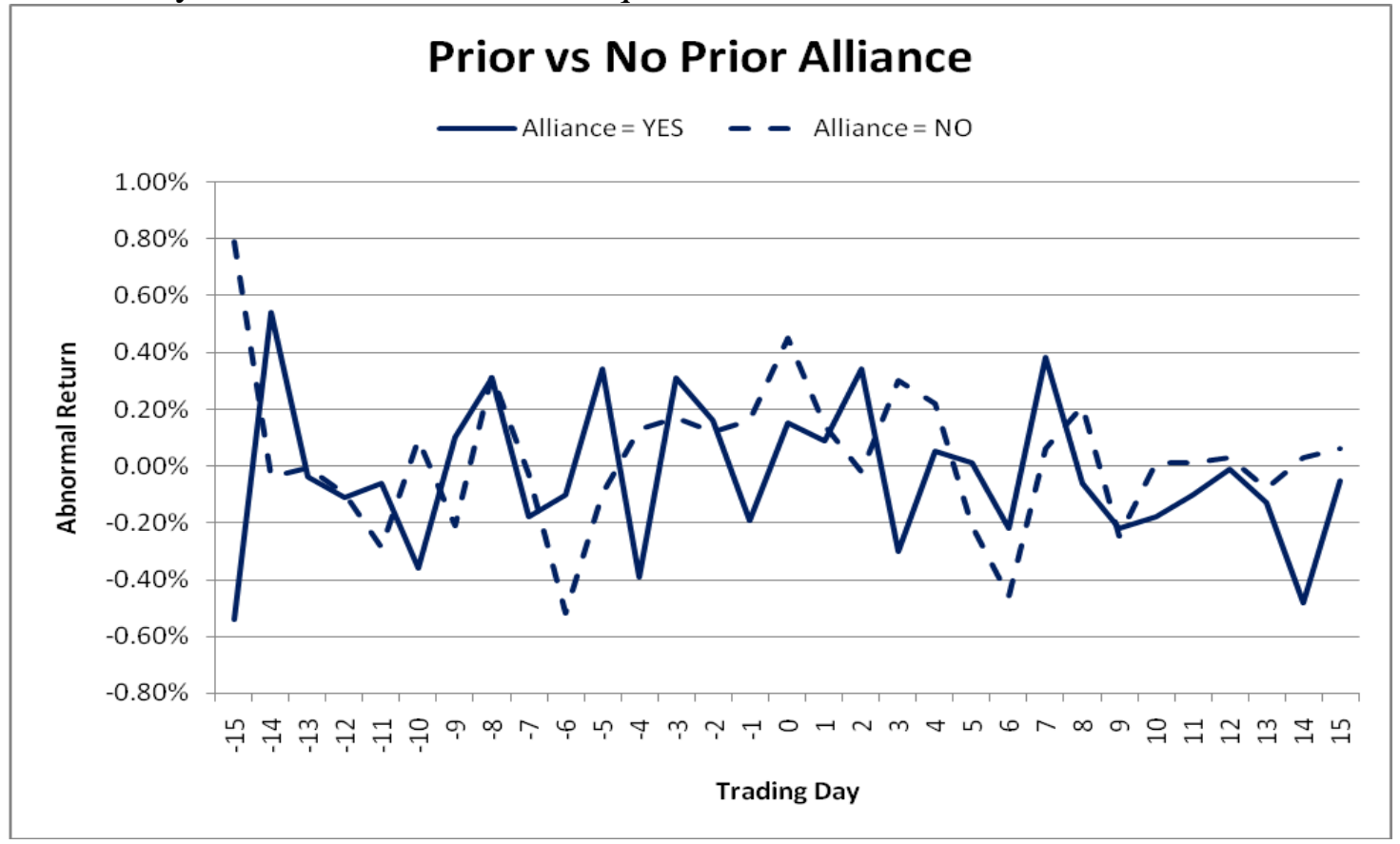


Figure 2b

Daily Abnormal Returns for Foreign and Domestic Acquisitions with Prior Alliances

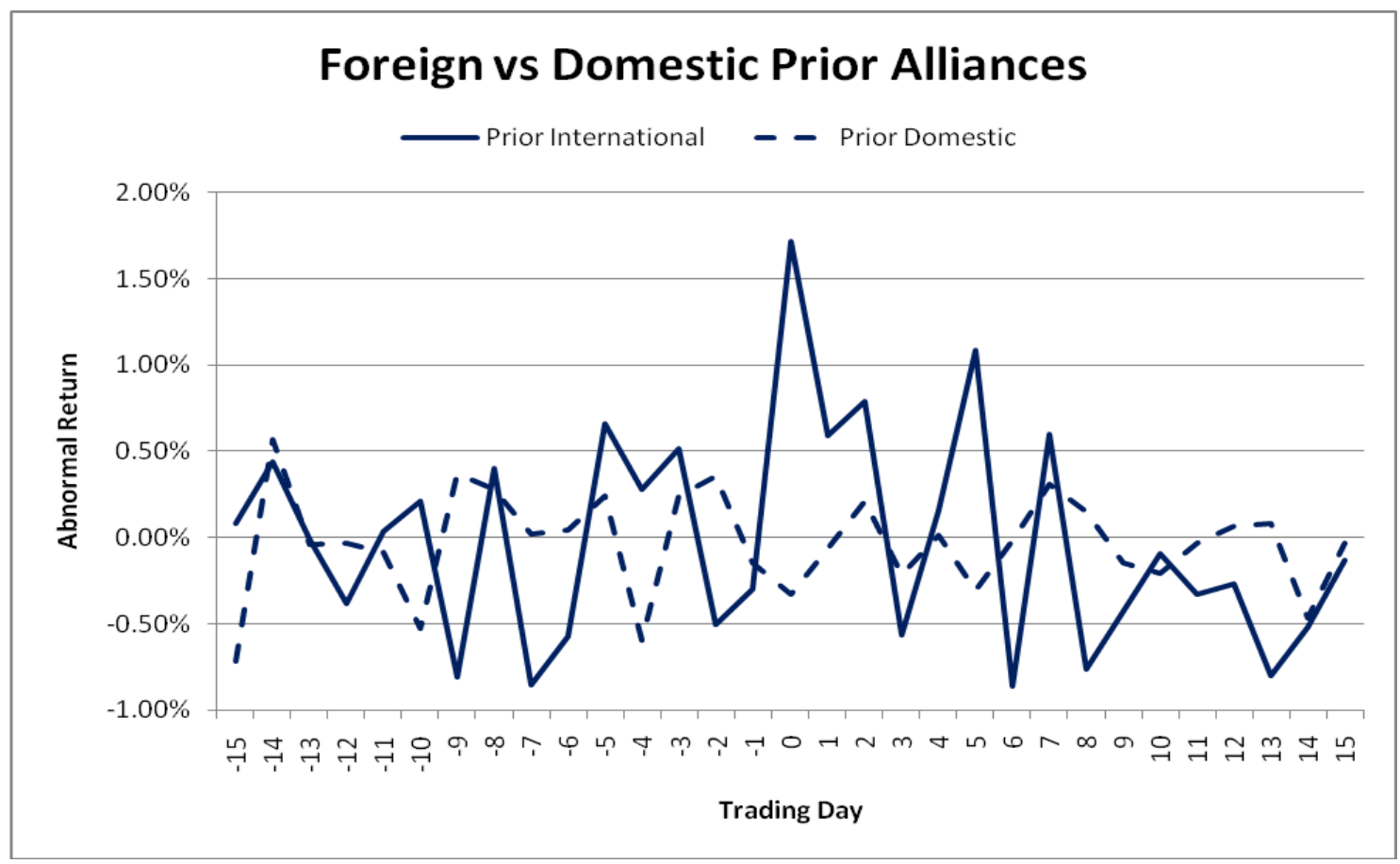

Figure 2c

Daily Abnormal Returns for Acquisitions with Prior Strong and Weak Alliances

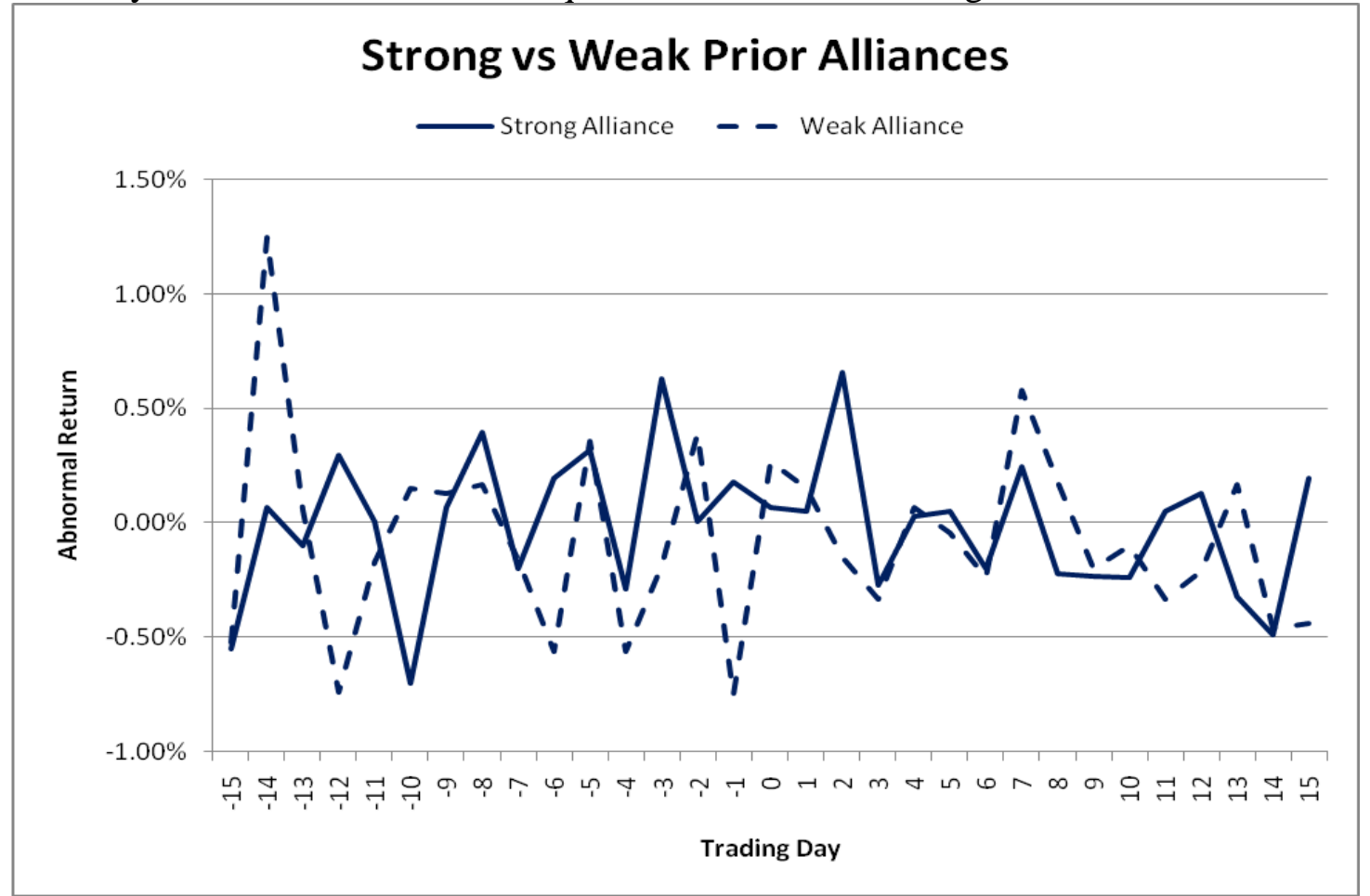


Table 1

Descriptive Statistics of Daily and Cumulative Abnormal Returns

\begin{tabular}{|c|c|c|c|c|c|c|}
\hline \multicolumn{7}{|c|}{ Panel A: Average Daily Abnormal Returns (Full Sample) } \\
\hline Day & $\mathrm{N}$ & Mean AR & Patell Z & Boehmer Z & Pos/Neg & Rank Z \\
\hline-15 & 417 & $0.12 \%$ & 0.606 & 0.564 & 1.02 & 0.250 \\
\hline-14 & 417 & $0.25 \%$ & $1.340+$ & 0.945 & 0.95 & 0.460 \\
\hline-13 & 417 & $-0.02 \%$ & -0.021 & -0.021 & 0.87 & -0.670 \\
\hline-12 & 417 & $-0.11 \%$ & -0.238 & -0.236 & 0.90 & -0.880 \\
\hline-11 & 417 & $-0.18 \%$ & -0.668 & -0.687 & 0.82 & -0.780 \\
\hline-10 & 417 & $-0.14 \%$ & $-1.346+$ & $-1.323+$ & 0.77 & $-1.670 *$ \\
\hline-9 & 417 & $-0.06 \%$ & 0.112 & 0.118 & 0.89 & 0.010 \\
\hline-8 & 417 & $0.31 \%$ & $1.683 *$ & $1.631+$ & 1.03 & $1.560+$ \\
\hline-7 & 417 & $-0.11 \%$ & -0.740 & -0.724 & 0.84 & -0.690 \\
\hline-6 & 417 & $-0.31 \%$ & -1.655 & $-1.508+$ & 0.78 & $-2.010 *$ \\
\hline-5 & 417 & $0.12 \%$ & 0.781 & 0.767 & 0.86 & 0.550 \\
\hline-4 & 417 & $-0.14 \%$ & $-1.386+$ & $-1.376+$ & 0.85 & -1.040 \\
\hline-3 & 417 & $0.24 \%$ & $1.352+$ & 1.229 & 0.94 & 0.810 \\
\hline-2 & 417 & $0.14 \%$ & 0.221 & 0.204 & 1.06 & 0.880 \\
\hline-1 & 417 & $-0.01 \%$ & 0.551 & 0.521 & 0.88 & 0.000 \\
\hline 0 & 417 & $0.30 \%$ & $1.600+$ & 1.134 & 1.03 & 1.040 \\
\hline 1 & 417 & $0.11 \%$ & 0.907 & 0.641 & 0.98 & 0.380 \\
\hline 2 & 417 & $0.16 \%$ & $1.508+$ & $1.453+$ & 0.95 & 0.750 \\
\hline 3 & 417 & $0.00 \%$ & -0.853 & -0.816 & 0.85 & -1.210 \\
\hline 4 & 416 & $0.13 \%$ & 0.873 & 0.870 & 1.02 & 0.840 \\
\hline 5 & 416 & $-0.10 \%$ & -0.868 & -0.856 & 0.86 & -0.860 \\
\hline 6 & 416 & $-0.34 \%$ & -1.648 & $-1.460+$ & 0.85 & $-1.320+$ \\
\hline 7 & 416 & $0.22 \%$ & $1.282+$ & 1.247 & 0.92 & 0.870 \\
\hline 8 & 416 & $0.07 \%$ & 0.597 & 0.594 & 0.98 & 0.590 \\
\hline 9 & 416 & $-0.23 \%$ & $-1.786 *$ & $-1.766 *$ & 0.83 & $-1.800 *$ \\
\hline 10 & 416 & $-0.09 \%$ & -0.261 & -0.231 & 0.81 & -0.790 \\
\hline 11 & 416 & $-0.05 \%$ & -0.606 & -0.648 & 0.92 & -0.990 \\
\hline 12 & 416 & $0.01 \%$ & 0.154 & 0.147 & 0.86 & -0.290 \\
\hline 13 & 416 & $-0.10 \%$ & -0.436 & -0.406 & 0.73 & -1.250 \\
\hline 14 & 416 & $-0.23 \%$ & $-1.592+$ & $-1.584+$ & 0.71 & $-2.140 *$ \\
\hline 15 & 416 & $0.00 \%$ & 0.206 & 0.191 & 0.85 & -0.540 \\
\hline \multicolumn{7}{|c|}{ Panel B: Cumulative Abnormal Returns for Various Windows (Full Sample) } \\
\hline Window & $\mathrm{N}$ & Mean AR & Patell Z & Boehmer Z & Pos/Neg & Rank Z \\
\hline$(-15,+15)$ & 417 & $0.01 \%$ & -0.045 & -0.048 & 0.93 & $-1.786 *$ \\
\hline$(-10,+10)$ & 417 & $0.31 \%$ & 0.193 & 0.196 & 1.00 & -0.678 \\
\hline$(-5,+5)$ & 417 & $0.96 \%$ & $1.370+$ & 1.236 & 1.14 & 0.646 \\
\hline$(-5,+1)$ & 417 & $0.76 \%$ & $1.501+$ & $1.306+$ & 1.21 & 0.991 \\
\hline$(-1,+1)$ & 417 & $0.40 \%$ & 1.773 & $1.316+$ & 0.91 & 0.823 \\
\hline$(-1,0)$ & 417 & $0.29 \%$ & 1.530 & 1.237 & 0.93 & 0.737 \\
\hline \multicolumn{7}{|c|}{ Panel C: Cumulative Abnormal Returns in $[-5,5]$ (Various Subsamples) } \\
\hline Subsample & $\mathrm{N}$ & Mean AR & Patell Z & Boehmer Z & Pos/Neg & Rank Z \\
\hline Prior Alliance & 211 & $0.57 \%$ & -0.120 & -0.105 & 0.92 & -0.259 \\
\hline No Prior Alliance & 206 & $1.37 \%$ & $2.071 *$ & $1.943 *$ & 1.42 & 1.159 \\
\hline Prior Foreign & 49 & $4.43 \%$ & $2.298 *$ & $1.766^{*}$ & 1.23 & $1.761 *$ \\
\hline Prior Domestic & 162 & $-0.60 \%$ & $-1.401+$ & $-1.300+$ & 0.84 & -1.256 \\
\hline Prior Strong & 128 & $1.44 \%$ & 0.459 & 0.375 & 0.88 & -0.262 \\
\hline Prior Weak & 83 & $-0.77 \%$ & -0.761 & -0.750 & 0.98 & -0.089 \\
\hline
\end{tabular}

$+\mathrm{p}<0.10,{ }^{*} \mathrm{p}<0.05,{ }^{* *} \mathrm{p}<0.01, * * * \mathrm{p}<0.001$ 
Table 2

Summary Statistics and Correlations

\begin{tabular}{|c|c|c|c|c|c|c|c|c|c|c|c|c|}
\hline \multirow[b]{2}{*}{ Variable } & \multicolumn{4}{|c|}{ Descriptive Statistics } & \multicolumn{8}{|c|}{ Correlations } \\
\hline & Mean & SD & Min & Max & 1 & 2 & 3 & 4 & 5 & 6 & 7 & 8 \\
\hline 1 Performance & 0.01 & 0.12 & -0.33 & 0.79 & & & & & & & & \\
\hline 2 Related Acquisition & 0.63 & 0.48 & 0 & 1 & -0.041 & & & & & & & \\
\hline 3 Public Target & 0.16 & 0.36 & 0 & 1 & -0.015 & 0.073 & & & & & & \\
\hline 4 Considerations & 1.25 & 0.59 & 1 & 5 & 0.146 & -0.037 & -0.028 & & & & & \\
\hline 5 Acquirer Total Assets & 3914.18 & 10192.38 & 2.57 & 81091 & -0.058 & -0.090 & 0.094 & -0.111 & & & & \\
\hline 6 Acquisition Experience & 7.29 & 10.04 & 0 & 72 & -0.076 & -0.002 & 0.074 & -0.105 & 0.639 & & & \\
\hline 7 Foreign Target & 0.21 & 0.41 & 0 & 1 & 0.035 & 0.068 & -0.104 & -0.057 & -0.051 & -0.068 & & \\
\hline 8 Prior Alliance & 0.50 & 0.50 & 0 & 1 & -0.033 & -0.001 & -0.005 & -0.018 & 0.014 & -0.028 & 0.060 & \\
\hline 9 Prior Alliance Strength & 2.85 & 1.25 & 1 & 4 & 0.063 & -0.008 & 0.139 & -0.002 & 0.018 & -0.008 & -0.012 & $\mathrm{~N} / \mathrm{A}^{\wedge}$ \\
\hline
\end{tabular}

$\wedge$ Prior Alliance Strength is observed only if Prior Alliance $=1$. Thus, the correlation between the two variables is undefined. 


\section{Table 3}

Effects of Prior Alliances on Acquisition Performance Dependent variable: Cumulative Abnormal Returns [-5,5]

(Standard Errors in Parentheses)

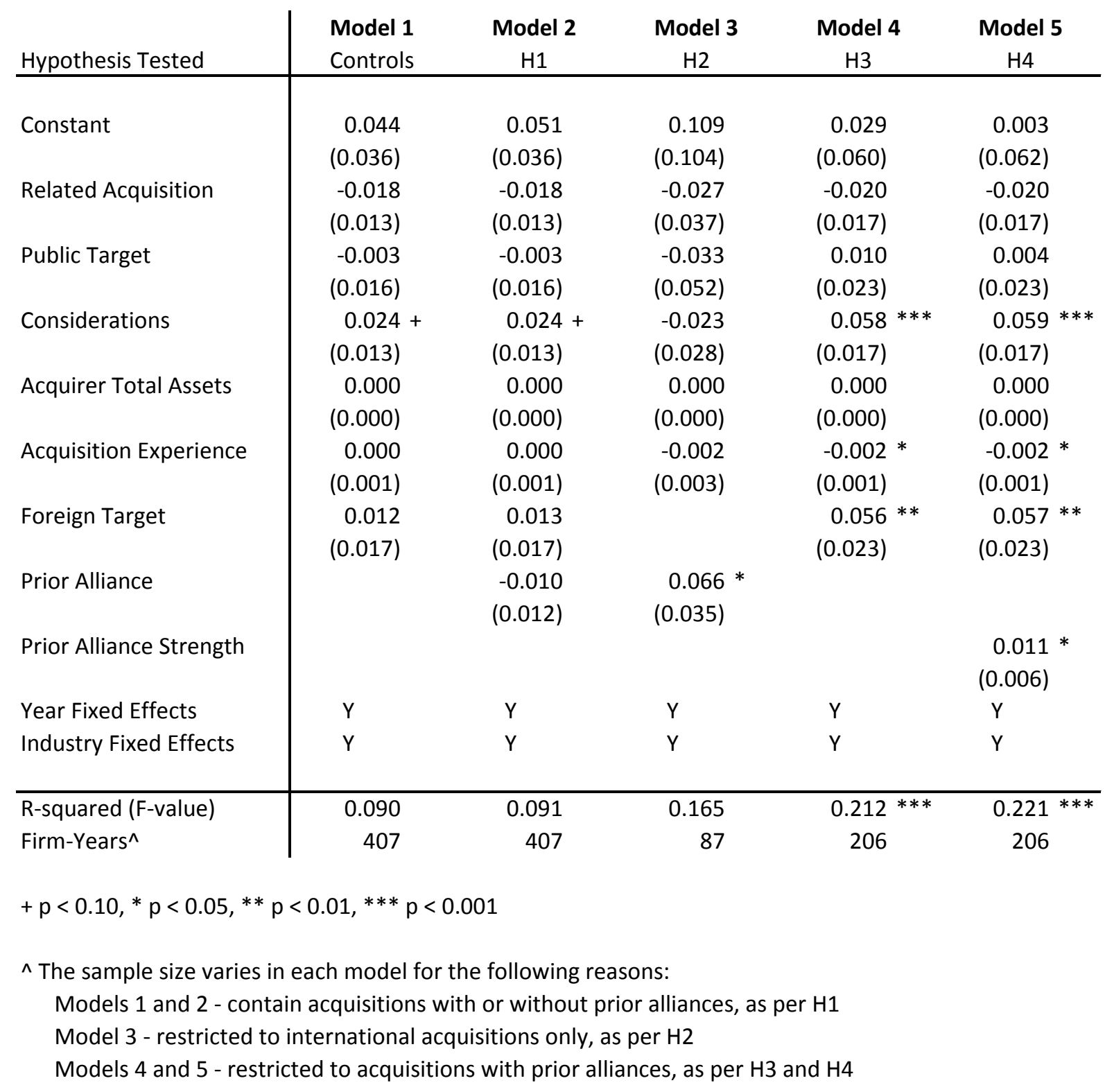

Note: The dependent variable in the regressions is the level of abnormal returns for each firm (rather than the difference between subgroups of interest). We test for differences in CARs between groups with and without prior alliances through the variables prior alliance, foreign target, and prior alliance strength depending on the relevant hypothesis. 
Appendix

Examples of Public Announcements of Different Alliance Types

\begin{tabular}{|c|c|c|}
\hline Type & Partners & Relevant Text \\
\hline Equity & $\begin{array}{l}\text { Viewlogic } \\
\text { Sunrise Test } \\
\text { Systems }\end{array}$ & $\begin{array}{l}\text { 7 June 1993. Viewlogic Systems... today announced that it has } \\
\text { reached an agreement to make a direct investment in Sunrise Test } \\
\text { Systems... Under the terms of the investment with Sunrise, a } \\
\text { Viewlogic executive will sit as an observer on Sunrise's board of } \\
\text { directors. }\end{array}$ \\
\hline Licensing & $\begin{array}{l}\text { Cisco } \\
\text { American Internet } \\
\text { Co. }\end{array}$ & $\begin{array}{l}20 \text { April 1998. American Internet....and Cisco Systems today } \\
\text { announced a multi-year, multi-million dollar agreement under which } \\
\text { Cisco... will OEM American Internet's Network Registrar products as } \\
\text { part of its CiscoAssure Policy Networking initiative. }\end{array}$ \\
\hline Supplier & $\begin{array}{l}\text { Solectron } \\
\text { Ericsson }\end{array}$ & $\begin{array}{l}25 \text { March 1997. Solectron Corporation...today announced the } \\
\text { signing of a memorandum.... with Ericsson Telecom AB to establish a } \\
\text { strategic, global manufacturing partnership...Ericsson's Infocom } \\
\text { Systems...has chosen Solectron as one of its primary outsourcing } \\
\text { partners. This relationship will position Solectron as a preferred } \\
\text { supplier for Ericsson... }\end{array}$ \\
\hline R\&D & $\begin{array}{l}\text { Schering-Plough } \\
\text { Canji Inc. }\end{array}$ & $\begin{array}{l}26 \text { October 1994. Schering-Plough Corp. and Canji... announced a } \\
\text { strategic research agreement to develop new cancer treatments } \\
\text { based on Canji's proprietary scientific discoveries with p53 gene } \\
\text { therapy technology... Robert P. Luciano, Schering-Plough [CEO } \\
\text { said,] “...this effort promises to harness a new therapeutic } \\
\text { technology to reverse or suppress an underlying cause of cancer." } \\
\text {... Additional p53-based treatments for other cancers would be } \\
\text { expected to follow; as approximately } 50 \text { percent of all human } \\
\text { cancers are associated with defective p53 genes...Schering-Plough } \\
\text { will be responsible for toxicology, safety and clinical trials. }\end{array}$ \\
\hline Marketing & $\begin{array}{l}\text { Hewlett-Packard } \\
\text { Verifone Inc. }\end{array}$ & $\begin{array}{l}6 \text { May 1996. Hewlett-Packard...and Verifone today announced a } \\
\text { broad global agreement to provide their scalable payment- } \\
\text { processing solution to financial-services institutions. The two } \\
\text { companies jointly will market and sell Verifone's Omnihost } 2.0 \\
\text { client-server software application running on the HP } 9000 \text { family of } \\
\text { enterprise servers ... HP and Verifone's agreement also calls for } \\
\text { collaborative activities in other areas, including Internet } \\
\text { commerce and smart-card applications... "Combining Verifone's } \\
\text { leadership and expertise as a global provider of security-enhanced } \\
\text { payment solutions and HP's well-known technical and industry } \\
\text { strengths results in a multitalented team able to effectively address } \\
\text { customer needs," said George Hoyem, vice president, Software } \\
\text { Marketing Group for Verifone. "By uniting our efforts across the } \\
\text { board -- in marketing, sales and research -- we can enable the } \\
\text { financial-services industry to streamline payment processing." }\end{array}$ \\
\hline
\end{tabular}

